\title{
Four Projection Streams from Primate V1 to the Cytochrome Oxidase Stripes of V2
}

\author{
Frederick Federer, ${ }^{1,2}$ Jennifer M. Ichida, ${ }^{1}$ Janelle Jeffs,,${ }^{1,3}$ Ingo Schiessl, ${ }^{4}$ Niall McLoughlin, ${ }^{4}$ and Alessandra Angelucci ${ }^{1}$ \\ ${ }^{1}$ Department of Ophthalmology, Moran Eye Center, ${ }^{2}$ Neuroscience Program, and ${ }^{3}$ Department of Bioengineering, University of Utah, Salt Lake City, Utah \\ 84132, and 4 Faculty of Life Sciences, University of Manchester, Manchester M13 9PT, United Kingdom
}

In the primate visual system, areas V1 and V2 distribute information they receive from the retina to all higher cortical areas, sorting this information into dorsal and ventral streams. Therefore, knowledge of the organization of projections between V1 and V2 is crucial to understand how the cortex processes visual information. In primates, parallel output pathways from $\mathrm{V} 1$ project to distinct $\mathrm{V} 2$ stripes. The traditional tripartite division of V1-to-V2 projections was recently replaced by a bipartite scheme, in which thin stripes receive V1 inputs from blob columns, and thick and pale stripes receive common input from interblob columns. Here, we demonstrate that thick and pale stripes, instead, receive spatially segregated V1 inputs and that the interblob is partitioned into two compartments: the middle of the interblob projecting to pale stripes and the blob/interblob border region projecting to thick stripes. Double-labeling experiments further demonstrate that $\mathrm{V} 1$ cells project to either thick or pale stripes, but rarely to both. We also find laminar specialization of V1 outputs, with layer $4 \mathrm{~B}$ contributing projections mainly to thick stripes, and no projections to one set of pale stripes. These laminar differences suggest different contribution of magno, parvo, and konio inputs to each $\mathrm{V} 1$ output pathway. These results provide a new foundation for parallel processing models of the visual system by demonstrating four V1-to-V2 pathways: blob columns-to-thin stripes, blob/interblob border columns-to-thick stripes, interblob columns-to-pale lateral $_{\text {stripes, layer 2/3-4A interblobs-to-pale }}$ medial stripes.

\section{Introduction}

The primate primary visual cortex (V1) sends most of its output to area $\mathrm{V} 2$ in the form of multiple functionally specialized pathways, which segregate into distinct V2 modules [the thick, thin, and pale cytochrome oxidase (CO) stripes]. Livingstone and Hubel $(1984,1987,1988)$ first proposed three parallel V1-to-V2 pathways, for the processing of color, form, and motion/stereopsis, respectively: (1) layer $2 / 3$ CO blobs to thin stripes, (2) layer $2 / 3$ interblobs to pale stripes, and (3) layer $4 \mathrm{~B}$ to thick stripes (Fig. $1 A)$. Recently, Sincich and Horton (2002) revised this model. Based on qualitative observations, they proposed that all stripe types receive inputs from the same V1 layers $(2 / 3,4 \mathrm{~A}, 4 \mathrm{~B}, 5 / 6)$ and that their V1 input is tangentially segregated into only two pathways: (1) CO blob columns to thin stripes, (2) interblob columns to pale and thick stripes (Fig. $1 B$ ).

However, several observations suggest that pale and thick stripes may instead receive segregated V1 inputs. First, beyond V2 visual information is processed into two functionally specialized streams, a dorsal stream for spatial vision and a ventral stream for object vision (DeYoe and Van Essen, 1988; Zeki and Shipp, 1988;

\footnotetext{
Received March 19, 2009; revised 0ct. 9, 2009; accepted 0ct. 26, 2009.

This work was supported by National Science Foundation Grants IBN-0344569 and IOS-0848106 (A.A.), National Institutes of Health Grants EY015262 and EY019743 (A.A.) and EY015609 (J.M.I.), and Wellcome Trust Grant 061113, and by a grantfrom Research to Prevent Blindness, Inc. (Department of Ophthalmology, University ofUtah). WethankKesiSainsbury for excellent technical assistance, Dr. Emanuele Leoncini for advice on statistical analyses, Prof. Francisco Clasca for advice on data analysis, and Prof. Vivien Casagrande for comments on a previous version of this manuscript.

Correspondence should be addressed to Alessandra Angelucci, 65 Mario Capecchi Drive, Salt Lake City, UT 84132. E-mail: alessandra.angelucci@sc.utah.edu.

DOI:10.1523/JNEUROSCI.1648-09.2009

Copyright $\odot 2009$ Society for Neuroscience $\quad 0270-6474 / 09 / 2915455-17 \$ 15.00 / 0$
}

Merigan and Maunsell, 1993; Ungerleider and Haxby, 1994). V2 thick and pale stripes segregate their outputs to dorsal and ventral stream areas, respectively (DeYoe and Van Essen, 1985; Shipp and Zeki, 1985); thus, rather than a common message, they may relay specialized information from V1 to downstream areas. Second, thick and pale stripes show distinct functional specialization, suggestive of distinct V1 inputs; for example, thick, but not pale, stripes show a map of retinal disparity (Chen et al., 2008). Third, in primate V1, the area occupied by the CO blobs is small (20-30\%) (Purves and LaMantia, 1993; Solomon, 2002) compared with the interblob area. Projections from the interblob to the thick and pale stripes have not been previously analyzed quantitatively for spatial segregation, leaving unclear whether cells projecting to these two stripe types are spatially intermingled or segregated. Therefore, additional interblob specialization remains a possibility.

To test the hypothesis that pale and thick stripes receive segregated V1 inputs, here we have quantified the tangential and laminar distribution of cell label in V1 after injections of neuroanatomical tracers into different $\mathrm{V} 2$ stripe types, some of which were functionally identified using optical imaging. We find both laminar and tangential specialization in the origin of the V1 output pathways to V2. Although all stripe types receive dominant $\mathrm{V} 1$ inputs from layers $2 / 3$ and weaker inputs from layer $4 \mathrm{~A}$, layer $4 \mathrm{~B}$ contributes significant projections only to thick stripes and no projections to one set of pale stripes ( pale $_{\text {medial }}$ ). Additionally, V1-to-V2 projections are segregated in the tangential domain, with thin stripes receiving projections from CO blobs, pale stripes from interblobs, and thick stripes from the blob/interblob border region, which we identify as a distinct V1 compartment. Double- 


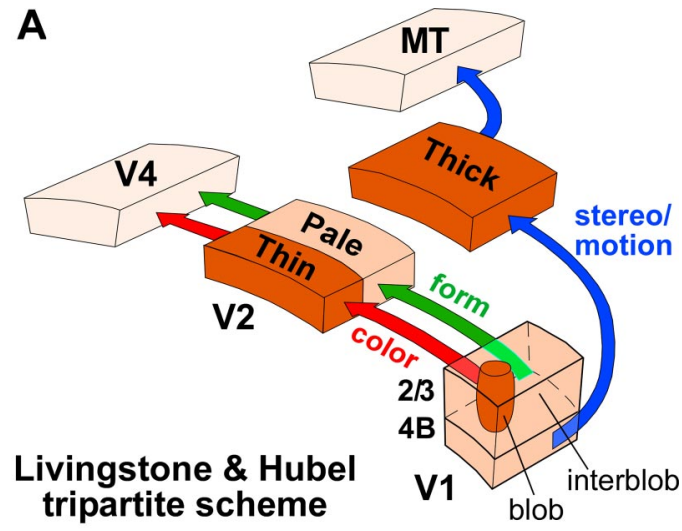

B

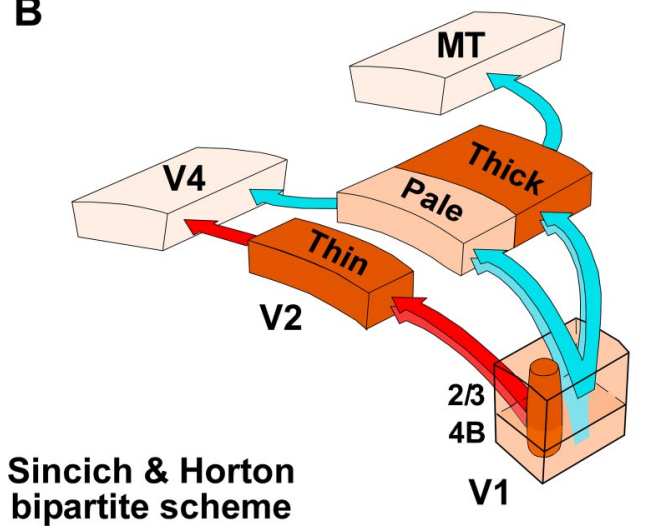

Figure 1. Previously proposed schemes of projections from V1 to V2. $A$, The tripartite scheme proposed by Livingstone and Hubel in which layer $2 / 3 \mathrm{CO}$ blobs project to thin stripes, layer $2 / 3$ interblobs project to pale stripes, and cells in layer $4 B$ project to thick stripes. These authors also proposed that these V1-to-V2 pathways subserve a tripartite division of color, form, and motion/depth information processing, as indicated. Others (DeYoe and Van Essen, 1985; Shipp and Zeki, 1985) then showed that the thick stripes project to MT (an area specialized in the processing of motion and stereopsis), and the thin and pale stripes to V4 (an area specialized in the processing of color and form). $\boldsymbol{B}$, The bipartite scheme proposed by Sincich and Horton (2002) in which cells in layers $2 / 3,4 A$ (data not shown), 4B, and $5 / 6$ (data not shown) within $C 0$ blobs project to thin stripes, and cells in layers $2 / 3,4 A, 4 B$, and $5 / 6$ in the interblobs project to both pale and thick stripes.

labeling experiments additionally demonstrate that individual blob or interblob cells project predominantly to a single stripe type. These data support a quadripartite division of V1-to-V2 pathways.

\section{Materials and Methods}

To determine how many pathways to V2 leave V1, small injections of different retrograde neuroanatomical tracers were targeted to specific V2 stripes, identified in vivo using intrinsic signal optical imaging, or were made blindly into V2 of marmoset monkeys using stereotaxic coordinates. The tangential and laminar distribution of resulting cell label in V1 was analyzed quantitatively.

Animals. A total of 87 tracer injections were made in 19 adult marmosets, obtained from an in-house colony (many of these animals were also used for other unrelated projects), in accordance with protocols approved by the University of Utah Institutional Animal Care and Use Committee and the British Home Office. Each animal received 3-10 tracer injections in dorsal area V2 of one hemisphere and, in some instances, 2-4 injections in the opposite hemisphere. Injections were targeted using stereotaxic coordinates, except in four cases in which the tracers were targeted to specific V2 stripes functionally identified in vivo using intrinsic signal optical imaging. Within the same hemisphere, we either injected different tracers or made two injections of the same tracer(s) spaced at least $5 \mathrm{~mm}$ apart, to ensure no overlap of the resulting labeled fields in V1. We never injected the same tracer in the two hemispheres of a single animal, to avoid labeling of callosal connections. Of 87 tracer injections, only those $(n=28)$ that were clearly confined to a single V2 stripe type were included in the analysis, and 23 were analyzed quantitatively (the latter cases are listed in Tables 1 and 4). The remainder of the injections were rejected because they straddled stripes or areas adjacent to V2, did not result in detectable cell label in V1, or were located in an unidentifiable stripe. Some cases in which the injections were located cleanly in a single stripe were analyzed only qualitatively, and were not used for quantitative analysis, either because CO staining of the blobs was not optimal for image processing, or because the label was located in a nontangentially sectioned region at the posterior edge of V1. Of the 12 animals listed in Tables 1 and 4, six were males and six were females.

We performed these experiments in the marmoset monkey (Callithrix jacchus, a diurnal New World simian) for two reasons. First, unlike in the macaque in which most of V2 is buried in the lunate sulcus, marmoset V2 lies on the exposed cortical surface, making it easily accessible for optical imaging and tracer injections. Second, the smooth cortex of the marmoset can be more easily unfolded and flattened before CO staining, allowing for reliable identification of the V2 stripes. Although these anatomical experiments are feasible in macaque, they are considerably more difficult and would require a larger number of injections to be discarded (Sincich and Horton, 2002).

CO staining of tangential sections of marmoset V1 and V2 delineates the cortical layers and reveals the characteristic patterns (blobs and interblobs in V1, thin, thick, and pale stripes in V2) (see Fig. 6C) seen in areas V1 and V2 of macaque and other New World primates (Rosa et al., 1997; Solomon, 2002; Jeffs et al., 2009a). Anatomical (Lyon and Kaas, 2001; Solomon, 2002; Rosa et al., 2005; Palmer and Rosa, 2006; Jeffs et al., 2009a), electrophysiological (Rosa and Schmid, 1995; Fritsches and Rosa, 1996; Sengpiel et al., 1996; Rosa and Elston, 1998; Rosa and Tweedale, 2000), and optical imaging (Schiessl and McLoughlin, 2003; Roe et al., 2005; McLoughlin and Schiessl, 2006) studies of marmoset striate and extrastriate cortex have revealed geniculocortical and corticocortical connections, receptive field properties, and functional maps similar to those of macaque. Therefore, it is possible that the connectivity between V1 and V2 CO compartments in marmosets resembles that of macaques. However, differences between the two species are possible (see Discussion).

Surgical and tracer injection procedures. Animals were preanesthetized with ketamine $(25 \mathrm{mg} / \mathrm{kg}$, i.m.), intubated with an endotracheal tube, placed in a stereotaxic apparatus, and artificially ventilated. In animals that did not undergo optical imaging, anesthesia was maintained with isoflurane $(0.5-2 \%)$ in a mixture of 1:1 oxygen and nitrous oxide, and surgery was performed as described in detail previously (Jeffs et al., 2009a). The tracers injected are listed in Tables 1 and 4. Cholera toxin B (CTB) [1\% in $0.1 \mathrm{~m}$ phosphate buffer (PB), pH 6.0; low salt; List Biological Laboratories] and fluororuby (FR) (3000 and 10,000 MW mixed 1:1; $5 \%$ in $0.1 \mathrm{M} \mathrm{PB}$ saline, $\mathrm{pH} 7.3$; Invitrogen) were delivered iontophoretically using positive current in $7 \mathrm{~s}$ on/off cycles for $8-10$ and $15 \mathrm{~min}$, respectively. All other tracers were pressure injected using glass micropipettes (35-45 $\mu \mathrm{m}$ tip diameter) and a picospritzer in the following concentrations and volumes: gold-conjugated CTB (CTBg) (List Biological Laboratories), $0.1 \%$ in distilled water, 30-90 nl; CTB-Alexa-488, -555, and $-647\left(\mathrm{CTB}_{488}, \mathrm{CTB}_{555}\right.$, and $\mathrm{CTB}_{647}$, respectively; Invitrogen), $3 \%$ in distilled water, 15-40 nl; diamidino yellow (DY) (Sigma-Aldrich), 2\% in distilled water, 15-45 nl; and fast blue (FB) (EMS-Chemie), 5\% in distilled water, 15-45 nl. All tracers were delivered at a cortical depth of 800 $\mu \mathrm{m}$. These parameters typically yielded injection sites of $\sim 350-550 \mu \mathrm{m}$ in diameter. After the injections, animals were recovered from anesthesia and perfused, after 5-14 d, with saline for $2-3 \mathrm{~min}$ followed by $2 \%$ paraformaldehyde in $0.1 \mathrm{M}$ phosphate buffer for $5 \mathrm{~min}$.

Optical imaging. Intrinsic signal optical imaging was used to identify V2 stripes containing orientation maps. Animals were anesthetized (sodium thiopental; $2 \mathrm{mg} \cdot \mathrm{kg}^{-1} \cdot \mathrm{h}^{-1}$ ), paralyzed with vecuronium bromide $\left(1 \mathrm{mg} \cdot \mathrm{kg}^{-1} \cdot \mathrm{h}^{-1}\right)$, and artificially ventilated. Depth of anesthesia was assessed continuously by monitoring end-tidal $\mathrm{CO}_{2}$, pulse oximetry, and electrocardiogram. A craniotomy and durotomy were performed to expose areas V1 and V2 and sealed with a stainless-steel chamber filled 
with silicone oil and secured to the skull. A reference image of the cortical surface vasculature (see Fig. $6 G$ ) was taken periodically under $546 \mathrm{~nm}$ illumination. This image was used later for analysis to remove vessel artifacts (Schiessl and McLoughlin, 2003) and to align the histological sections to the optical maps (as shown and described in Fig. 6G,H). Visual stimuli consisted of full-field, high-contrast (100\%) achromatic drifting square-wave gratings of eight different orientations, with a spatial frequency of $0.5-1.0$ cycles/deg, moving back and forth at $2.85 \mathrm{deg} / \mathrm{s}$ in directions perpendicular to the grating orientation. Imaging in response to these stimuli was performed under $720 \mathrm{~nm}$ monochromatic light; imaging and processing of the optical images were performed as detailed by McLoughlin and Schiessl (2006). Tracer injections (CTB and FR) were made, as described above, in the imaged V2 region on the second day of the experiment, and the animals were kept under anesthesia for 2 additional days before perfusion. Perfusion was performed as for the nonimaged animals.

Histology. The visual cortex was unfolded, flattened, postfixed between glass-slides for $1-2 \mathrm{~h}$, and frozen-sectioned tangentially at $40 \mu \mathrm{m}$. In the optically imaged cases, to avoid major tissue distortions, which would compromise accurate alignment of the images with the histological sections, no unfolding was performed; rather, the cortex was flattened gently above the imaged region. Every third section was stained for $\mathrm{CO}$ and digitized before being silver reacted to reveal CTBg. The remaining sections were reacted to reveal the other injected tracers. Specifically, CTB, $\mathrm{CTB}_{488}$, and FR were revealed immunohistochemically as described previously (Angelucci et al., 1996; Jeffs et al., 2009a). CTBg was revealed using silver intensification (Llewellyn-Smith et al., 1990). Sections containing $\mathrm{CTB}_{488}, \mathrm{CTB}_{555}, \mathrm{CTB}_{647}, \mathrm{FB}$, and DY were mounted immediately after sectioning and coverslipped using Gel Mount (Electron Microscopy Sciences).

Data analysis. Tracer injection sites in V2 and retrogradely labeled cells in $\mathrm{V} 1$ were plotted on live images of the tissue sections projected onto a computer monitor via a video camera. Label was plotted on all available sections (at least one in three) throughout the cortical thickness, using Neurolucida software (MicroBrightField). Fluorescent cells were plotted using 10-20× objectives, whereas CTBg and DAB-labeled cells were typically plotted under dark-field and bright-field illumination, respectively, using a $10 \times$ objective. In cases in which the CTBg label was paler, or unspecific background staining was higher, cells were plotted at higher magnification $(40 \times)$. The effective tracer uptake zone for immunoreacted $\mathrm{CTB}, \mathrm{CTB}_{488}$, and FR was defined as the region at the injection site in which no labeled cell bodies or fibers could be discerned (Ericson and Blomqvist, 1988; Luppi et al., 1990; Brandt and Apkarian, 1992; Angelucci et al., 1996). For CTBg, it was defined as the dark core seen under dark-field microscopy (Llewellyn-Smith et al., 1990). For $\mathrm{CTB}_{488,555,647}$, the tracer uptake zone was the dense core seen under fluorescence microscopy, in which no labeled cell bodies were visible, and for FB and DY, it was the region of tissue damage caused by the injected tracer (Condé, 1987), visible under fluorescence illumination.

The laminar location of the injection sites and of V1 labeled cells was determined by aligning single section plots to adjacent $\mathrm{CO}$-stained sections, using the radial blood vessel profiles, and by counterstaining all remaining sections for Nissl, after plotting cell label. Plots of cell label within a cortical layer were aligned using blood vessels and collapsed onto one plane. To determine the CO blob/interblob location of labeled cells, these composite layer-specific maps of label were aligned to the V1 CO blob map. To determine the areal and CO stripe location of the injection sites, $\mathrm{CO}$ staining was visualized and digitized at low magnification $(1.25 \times)$; typically three to six images of serial CO sections were overlaid by aligning the radial blood vessels and merged in Adobe Photoshop. We find that the stripe pattern is much clearer in these composite images than in any single CO section, in which the stripes can be incomplete. Composite injection sites were overlaid onto these CO images, and their areal and stripe location, cortical layers involved, and diameter (extent of longest axis) (see Tables 1,4) were determined. Areas V1 and V2 were identified on these images primarily based on their distinct $\mathrm{CO}$ staining pattern [i.e., CO blobs in the $\mathrm{V} 1$ upper layers or uniform dark CO staining in V1 layer 4C (Horton and Hubel, 1981; Humphrey and Hendrickson, 1983) and CO stripes in V2 (Tootell et al., 1983)]. Al- though our injection sites were typically located closer to the caudal than to the rostral border of V2, we also confirmed that the injections were restricted to V2, based on the laminar pattern of retrograde label in V1. Specifically, injections located just anterior to V2 resulted in dense label primarily in layers $4 \mathrm{~A} / 4 \mathrm{~B}$, and only very sparse label in layer $2 / 3$ (Jeffs et al., 2009b; Rosa et al., 2009). This pattern was essentially reversed after injections confined to V2 (Jeffs et al., 2009a,b).

Dark CO stripes were classified as thick (as opposed to thin) if they satisfied the following criteria: (1) they appeared thicker than the two adjacent dark stripes in CO staining, (2) tracer injections confined to these stripes produced label in area MT, and (3) they coincided with optically imaged regions having an orientation map, in cases in which optical imaging data were available. Alignment of the histological COstained sections with optical maps was performed as described in the legend to Figure 6, $G$ and $H$.

The relationship of V1-labeled cells to the CO blob compartments was quantified as described in Results.

Analysis of double-labeled cells. In four animals, paired injections of different tracers were made in adjacent stripe types ( $n=6$ injection pairs) or in the same stripe type ( $n=3$ injection pairs). The labeled fields resulting from each injection site were outlined, and their overlap area was measured and normalized to the area of the smallest labeled field; within the overlap area, the number of cells double labeled with both tracers was counted (see Table 3). To identify cells double labeled for $\mathrm{CTBg}$ and $\mathrm{CTB}_{488}$, the same tissue sections were first immunoreacted to reveal $\mathrm{CTB}_{488}$, and then silver-reacted for CTBg. The labeled cells were plotted under direct microscopic observation and bright-field illumination using a $64 \times$ objective; cells were scored as double-labeled if they showed cytoplasmic brown DAB product $\left(\mathrm{CTB}_{488}\right)$ and black silver grains (CTBg) in the same focal plane (supplemental Fig. $1 A-D$, available at www.jneurosci.org as supplemental material).

Cells double labeled with two different fluorescent tracers were analyzed and quantified using a confocal microscope. Specifically, each 40$\mu \mathrm{m}$-thick tangential section containing different types of fluorescently labeled cells (DY, $\mathrm{CTB}_{488}, \mathrm{CTB}_{555}, \mathrm{CTB}_{647}$ ) in $\mathrm{V} 1$ layer 2/3 was scanned at 5-8 $\mu \mathrm{m}$ scanning depth increments, using an Olympus FV1000 inverted laser-scanning confocal microscope with a $20 \times$ air objective; each section was scanned at each of the wavelengths needed to reveal each injected tracer. Two-dimensional stitched images of the label fields were generated for each color channel at each scanned depth, and images from different depths were aligned. Image files acquired at the confocal microscope were then imported into Neurolucida software, which allows rapid travel up and down the $z$-stack. The different types of labeled cells on these images were plotted using Neurolucida software. The opacity of the aligned color channel images were adjusted separately to identify cells that were excited by more than one channel of light (i.e., cells that were labeled with two or more fluorescent tracers) (supplemental Fig. $1 \mathrm{E}-\mathrm{H}$, available at www.jneurosci.org as supplemental material). As each laserscanned focal plane was very narrow, we could be confident that a cell excited by two different wavelengths on an image at a single depth was indeed double labeled. Furthermore, by moving up and down the $z$-stack, we could identify each cell at several depths in real time, and only mark the cell once. Once all of the labeled cells in V1 had been plotted through the entire depth of a section, the percentages of double-labeled cells was determined within the overlap area of the fields labeled with the two different fluorescent dyes.

We also determined whether the percentage of double-labeled cells correlates with the area of overlap of the two labeled fields, and whether both correlate with the distance between injection sites. The interinjection distance was measured in a plane orthogonal to the elongation of the CO stripes, as the gap between the lateral border of the medial-most injection and the medial border of the lateral-most injection. We measured interinjection distance across $\mathrm{CO}$ stripes, because magnification factor varies more rapidly across than along CO stripes (Rosa et al., 1997).

Analysis of the laminar distribution of labeled cells in V1. To quantify the laminar distribution of cell label in V1, the percentage of labeled cells in V1 layers $2 / 3,4 \mathrm{~B}$, and $5 / 6$ was calculated as described in Results. The density of labeled cells in layers $2 / 3\left(D_{2 / 3}\right)$ and $4 \mathrm{~B}\left(D_{4 \mathrm{~B}}\right)$ was measured as 
follows. In each tissue section within a cortical layer, kinked straight lines were drawn between the labeled cells at the outer edge of the labeled neuronal field. The area inside the resulting contour was measured and all labeled cells inside the contour were counted. The same procedure was repeated for each section within the same layer that contained labeled cells. We then summed the areas of all sections through a layer, to obtain the composite area of that layer. The density of labeled cells in that layer $(D)$ was then computed by dividing the total number of cells counted in the layer (across all sections) by that layer composite area. The density index (DI) for layer $2 / 3$ was calculated as follows: $\mathrm{DI}_{2 / 3}=D_{2 / 3} /\left(D_{2 / 3}+D_{4 \mathrm{~B}}\right)$; for layer $4 \mathrm{~B}$, it was $\mathrm{DI}_{4 \mathrm{~B}}=1-\mathrm{DI}_{2 / 3}$.

\section{Results}

First, we describe the tangential distribution of cell label in V1 resulting from injections of neuroanatomical tracers into specific V2 CO stripes. The laminar distribution of V1 label is described next.

\section{Tangential distribution of V1 cells projecting to $\mathrm{V} 2$}

To quantify the tangential distribution of cell label in V1 resulting from injections in different V2 stripe types, we aligned composite layer-specific plots of V1 label to the CO blob map and determined the relationship of labeled cells to the CO blobs, as follows. Digitized images of CO blobs were processed using low-pass and equalization filters (Image Pro software) (Fig. 2A,B). Blob centers were defined as the darkest spot within each blob, and the distance of each labeled cell to its nearest blob center was measured (Fig. 2C). The blob centers assigned by the image analysis software were visually inspected for accuracy. For circular blobs that showed more than one peak of maximum density (this happened infrequently), we chose the one that was closest to the geometric center of the blob. For blobs that showed significant elongation, we marked several centers; the latter in most cases coincided with multiple peaks in CO density along the length of the elongated blob, having similar center-tocenter spacing as the surrounding tissue.

For each case, we also determined the average blob radius, by first segmenting out the darkest $33 \%$ of pixels across the grayscale image to outline the blobs [as in the studies by Boyd and Casagrande (1999) and Sincich and Horton (2005)], and then measuring the distance to the blob center of several markers placed all around the outline of each blob (Fig. 2D). For each injection case, we determined the distribution of the cell distances to the nearest blob center, the median, mean, and SEM of this distribution, as well as the median and mean blob radius (Tables 1,2). The mean blob radius across all cases measured $131.1 \pm 0.78 \mu \mathrm{m}$. Although mean blob radius measured 120-140 $\mu \mathrm{m}$ for most cases, it could range between 109 and $151 \mu \mathrm{m}$. This variability may reflect a real variation in blob size across cases or across regions of $\mathrm{V} 1$, or may result from nonlinear variations in $\mathrm{CO}$ intensity across cases. To distinguish between these possibilities, for each case we also measured the center-to-center blob distance (i.e., the distance of each blob center to its nearest blob center). We found that the latter was positively and significantly correlated with blob radius ( $r=0.67$, Pearson's correlation) (supplemental Fig. 2, available at www.jneurosci.org as supple- mental material), indicating that there exists genuine variation in blob size across animals and/or V1 regions.

The results of the tangential analysis are described below, grouped by V2 stripe type.

\section{Thin stripe injections}

Injections confined to V2 thin stripes $(n=7)$ produced labeled cells primarily in layer $2 / 3$ within the CO blobs of V1. A typical case (250) is shown in Figure 3. Figure $3 A-C$ shows a CTBg injection site centered in, and confined to, a thin stripe. Resulting labeled cells in V1 layer 2/3 aligned preferentially with the CO blobs, but sparser label was also present in the interblobs (Fig. $3 D)$. In this layer, the median cell distance to the nearest blob center was $116 \mu \mathrm{m} ; 64 \%$ of cells were located within $140 \mu \mathrm{m}$ of the blob center, which was the median blob radius for this case (Fig. 3E, Table 1), and only $12 \%$ of cells lay in the middle of the interblobs (i.e., 200-250 $\mu \mathrm{m}$ from the blob center). Sparse label was also seen in layers $4 \mathrm{~A}$ and $4 \mathrm{~B}$. In other thin stripe injection cases, but not in this case, there was also sparse label in layer 5/6 (for a quantitative analysis of the laminar distribution of V1 label, see below). Quantification of the tangential distribution of cell label in layer $4 \mathrm{~B}$ showed that, as in layer $2 / 3$, labeled cells were mostly confined to the blobs (for the case in Fig. 3, the median cell distance in $4 \mathrm{~B}$ was $99.9 \mu \mathrm{m})$. We did not quantify label in layer $4 \mathrm{~A}$, but labeled cells in this layer also appeared mostly confined to the blobs.

The other thin stripe injection cases (one additional case is shown in Fig. $8 F-J$ ) showed similar results [quantification was performed for five cases (i.e., cases in which label was located mostly on a plane tangential to the pial surface and the quality of CO staining was optimal for image analysis)] (Table 1). Table 1 and Figure 7, $A$ and $B$, show the thin stripe population data (red bars) for the layer 2/3 label, and Figure $7 C$ shows the population data for layer $4 \mathrm{~B}$ label.

\section{Pale stripe injections}

Pale stripes in V2 are sandwiched between thin and thick stripes. Because previous studies suggested that there may be two func- 
Table 1. Tangential distribution of labeled cells in V1 layer 2/3: distance to nearest blob center

\begin{tabular}{|c|c|c|c|c|c|c|c|c|c|c|c|c|}
\hline \multirow[b]{2}{*}{ CO stripe } & \multirow[b]{2}{*}{ Case no. } & \multicolumn{3}{|c|}{ Injection sites } & \multicolumn{5}{|c|}{$\begin{array}{l}\text { \% Labeled V1 cells at each } \\
\text { distance from blob center }\end{array}$} & \multirow{2}{*}{$\begin{array}{l}\text { Distance from } \\
\text { blob center } \\
(\mu \mathrm{m}) \\
\text { Median }\end{array}$} & \multirow{2}{*}{$\begin{array}{l}\text { Blob radius } \\
(\mu \mathrm{m}) \\
\text { Median }\end{array}$} & \multirow[b]{2}{*}{ Figure } \\
\hline & & $\begin{array}{l}\text { Tracer } \\
\text { injected }\end{array}$ & $\begin{array}{l}\text { Layers } \\
\text { injected }\end{array}$ & $\begin{array}{l}\text { Diameter } \\
(\mathrm{mm})\end{array}$ & $\begin{array}{l}0-50 \\
(\mu \mathrm{m})\end{array}$ & $\begin{array}{l}50-100 \\
(\mu \mathrm{m})\end{array}$ & $\begin{array}{l}100-150 \\
(\mu \mathrm{m})\end{array}$ & $\begin{array}{l}150-200 \\
(\mu \mathrm{m})\end{array}$ & $\begin{array}{l}200-250 \\
(\mu \mathrm{m})\end{array}$ & & & \\
\hline \multirow[t]{5}{*}{ Thin } & $250^{a}$ & CTBg & $1-5$ & 0.36 & 13.0 & 29.3 & 26.2 & 19.6 & 11.9 & 115.8 & 140.3 & Fig. 3 \\
\hline & $274-m^{a}$ & CTBg & $1-6$ & 0.42 & 10.0 & 31.4 & 30.0 & 16.4 & 12.1 & 115.2 & 134.1 & Fig. $8 F-J$ \\
\hline & $271-m^{b}$ & CTBg & $1-4$ & 0.47 & 10.0 & 25.4 & 23.4 & 22.4 & 18.9 & 104.2 & 118.4 & \\
\hline & $233^{b}$ & СТВ 488 & $1-6$ & 0.57 & 10.5 & 26.9 & 30.4 & 22.8 & 9.3 & 122.5 & 106.3 & \\
\hline & $308-m^{b}$ & CTB 647 & $1-5$ & 0.30 & 16.0 & 30.2 & 29.4 & 15.8 & 8.6 & 104.4 & 139.1 & Supplemental Fig. $3^{C}$ \\
\hline \multirow[t]{6}{*}{ Thick } & $M^{b}$ & $\mathrm{CTB}$ & $1-6$ & $0.87 \times 0.28^{d}$ & 7.1 & 25.7 & 28.6 & 27.1 & 11.4 & 129.3 & 127.7 & Fig. 6 \\
\hline & $274{\mathrm{LH}-I^{a}}^{a}$ & $\mathrm{FR}$ & $1-3 B$ & 0.21 & 6.3 & 17.1 & 32.4 & 29.7 & 14.4 & 141.2 & 136.3 & Fig. 5 \\
\hline & $260-m^{a}$ & CTBg & $1-5 \mathrm{~A}$ & 0.37 & 5.0 & 14.8 & 25.8 & 33.6 & 20.7 & 157.2 & 135.6 & Fig. $8 A-E$ \\
\hline & $260-\left.\right|^{b}$ & CTBg & $2-4$ & 0.49 & 4.9 & 17.2 & 32.0 & 27.8 & 18.2 & 143.2 & 135.6 & \\
\hline & $S$ & CTB & $1-6$ & 0.49 & 5.3 & 17.3 & 26.5 & 27.6 & 23.2 & 151.4 & 131.9 & \\
\hline & $308-m^{b}$ & CTBg & $1-6$ & 0.46 & 5.8 & 18.3 & 23.1 & 30.3 & 22.5 & 154.1 & 139.1 & Supplemental Fig. $3^{c}$ \\
\hline \multirow[t]{4}{*}{ Pale $_{\text {lateral }}$} & $260-\mathrm{m}^{a}$ & CTB 488 & $1-4$ & 0.32 & 3.0 & 11.6 & 22.3 & 34.5 & 28.6 & 169.2 & 135.6 & Fig. $8 A-E$ \\
\hline & $274-m^{a}$ & CTB 488 & $1-6$ & 0.36 & 2.6 & 9.4 & 22.6 & 34.6 & 30.8 & 175.4 & 134.1 & Fig. $8 F-J$ \\
\hline & $259^{a}$ & $\mathrm{FB}$ & $1-5 A$ & 0.52 & 1.3 & 8.6 & 22.8 & 32.7 & 34.6 & 173.3 & 122.4 & \\
\hline & $308-m^{b}$ & СТВ 555 & $1-6$ & 0.25 & 2.0 & 7.4 & 18.9 & 34.9 & 36.8 & 182.6 & 139.1 & Supplemental Fig. $3^{c}$ \\
\hline \multirow[t]{4}{*}{ Pale $_{\text {medial }}$} & $282-I^{a}$ & CTBg & $1-6 A$ & 0.41 & 0.3 & 1.6 & 7.9 & 30.2 & 60 & 212.1 & 142.5 & Fig. 4 \\
\hline & $271-\left.\right|^{a}$ & CTBg & $1-5$ & 0.42 & 0.8 & 4.2 & 16.4 & 38.0 & 40.7 & 187.1 & 118.4 & Supplemental Fig. $6 B, C$ \\
\hline & $263^{a}$ & $\mathrm{FB}$ & $1-5$ & 1.22 & 1.4 & 6.0 & 18.2 & 35.3 & 39.1 & 185.6 & 140.8 & \\
\hline & $293^{b}$ & DY & $1-6$ & 0.54 & 0.1 & 3.6 & 17.9 & 39.1 & 39.3 & 188.2 & 121.2 & Supplemental Fig. $4 C-E^{c}$ \\
\hline \multicolumn{13}{|l|}{ Population } \\
\hline Thin stripes & $n=5$ & & & & & & & & & 113.7 & 125.5 & Fig. $7 A$ \\
\hline Thick stripes & $n=5$ & & & & & & & & & 151.4 & 125.6 & Fig. $7 A$ \\
\hline Pale $_{\text {lat }}$ stripes & $n=4$ & & & & & & & & & 175.3 & 135.1 & Fig. $7 A$ \\
\hline Pale $_{\text {med }}$ stripes & $n=4$ & & & & & & & & & 188.4 & 129.9 & Fig. $7 A$ \\
\hline
\end{tabular}

${ }^{a}$ Cases used for quantitative analyses in Figure $7, A$ and $C$.

${ }^{b}$ Cases used for quantitative analysis in Figure $7 \mathrm{~A}$.

'Available at www.jneurosci.org as supplemental material.

${ }^{d}$ Along versus across stripe.

Table 2. Distance to nearest blob center of labeled V1 layer 2/3 cells: statistical analysis

\begin{tabular}{|c|c|c|c|c|c|c|c|c|c|}
\hline \multirow[b]{2}{*}{ CO stripe } & \multirow[b]{2}{*}{ Case no. } & \multirow{2}{*}{$\begin{array}{l}\text { Tracer } \\
\text { injected }\end{array}$} & \multirow{2}{*}{$\begin{array}{l}\text { N labeled } \\
\text { cells }\end{array}$} & \multirow{2}{*}{$\begin{array}{l}\text { Mean } \\
\text { distance } \pm \text { SEM } \\
(\mu \mathrm{m})\end{array}$} & \multicolumn{2}{|c|}{$\begin{array}{l}95 \% \text { Confidence interval for } \\
\text { mean }(\mu \mathrm{m})\end{array}$} & \multirow{2}{*}{$\begin{array}{l}\text { Mean blob } \\
\text { radius } \pm \text { SEM }(\mu \mathrm{m})\end{array}$} & \multicolumn{2}{|c|}{$\begin{array}{l}95 \% \text { Confidence interval for } \\
\text { mean }(\mu \mathrm{m})\end{array}$} \\
\hline & & & & & Lower bound & Upper bound & & Lower bound & Upper bound \\
\hline \multirow[t]{5}{*}{ Thin } & 250 & CTBg & 4306 & $119.7 \pm 0.91$ & 117.9 & 121.5 & $145.1 \pm 2.75$ & 139.7 & 150.5 \\
\hline & $274-m$ & CTBg & 1333 & $120.8 \pm 1.59$ & 117.7 & 123.9 & $139.4 \pm 3.26$ & 133.0 & 145.9 \\
\hline & 271-m & CTBg & 196 & $111.0 \pm 3.84$ & 103.5 & 118.6 & $119.8 \pm 2.17$ & 115.6 & 124.1 \\
\hline & 233 & CTB 488 & 1399 & $122.4 \pm 1.48$ & 119.5 & 125.3 & $109.0 \pm 1.88$ & 105.3 & 112.7 \\
\hline & $308-m$ & CTB 647 & 2393 & $110.5 \pm 1.17$ & 108.2 & 112.8 & $139.0 \pm 2.58$ & 133.9 & 144.0 \\
\hline \multirow[t]{5}{*}{ Thick } & $M$ & CTB & 210 & $131.4 \pm 3.78$ & 123.9 & 138.8 & $131.7 \pm 4.06$ & 123.6 & 139.8 \\
\hline & 274LH-I & FR & 80 & $144.6 \pm 5.92$ & 132.9 & 156.4 & $137.5 \pm 3.35$ & 130.8 & 144.2 \\
\hline & $260-m$ & $\mathrm{CTBg}$ & 1503 & $150.5 \pm 1.42$ & 147.7 & 153.3 & $137.2 \pm 4.38$ & 128.5 & 145.9 \\
\hline & $260-1$ & $\mathrm{CTBg}$ & 802 & $144.4 \pm 1.97$ & 140.5 & 148.3 & $122.3 \pm 1.68$ & 119.0 & 125.6 \\
\hline & $308-m$ & $\mathrm{CTBg}$ & 1196 & $148.3 \pm 1.69$ & 145.0 & 151.6 & $139.0 \pm 2.58$ & 133.9 & 144.0 \\
\hline \multirow[t]{4}{*}{ Pale ${ }_{\text {lateral }}$} & $260-m$ & CTB 488 & 1667 & $161.8 \pm 1.30$ & 159.2 & 164.3 & $137.2 \pm 4.38$ & 128.5 & 145.9 \\
\hline & 274-m & CTB 488 & 3442 & $167.5 \pm 0.91$ & 165.7 & 169.3 & $139.4 \pm 3.26$ & 133.0 & 145.9 \\
\hline & 259 & $\mathrm{FB}$ & 541 & $167.6 \pm 2.14$ & 163.4 & 171.8 & $123.7 \pm 4.16$ & 115.3 & 132.1 \\
\hline & $308-m$ & CTB 555 & 1733 & $174.7 \pm 1.22$ & 172.3 & 177.1 & $139.0 \pm 2.58$ & 133.9 & 144.0 \\
\hline \multirow[t]{4}{*}{ Pale $_{\text {medial }}$} & $282-1$ & $\mathrm{CTBg}$ & 305 & $202.2 \pm 2.13$ & 198.0 & 206.4 & $150.5 \pm 3.70$ & 143.2 & 157.8 \\
\hline & $271-1$ & CTBg & 1741 & $181.8 \pm 1.04$ & 179.8 & 183.8 & $119.8 \pm 2.17$ & 115.6 & 124.1 \\
\hline & 263 & $\mathrm{FB}$ & 1581 & $178.5 \pm 1.23$ & 176.1 & 181.0 & $143.2 \pm 2.17$ & 139.0 & 147.5 \\
\hline & 293 & DY & 3698 & $183.5 \pm 0.68$ & 182.1 & 184.8 & $139.0 \pm 2.58$ & 117.6 & 126.8 \\
\hline \multicolumn{10}{|l|}{ Population } \\
\hline Thin stripes & & & 9627 & $117.8 \pm 0.59$ & 116.6 & 118.9 & $129.7 \pm 1.19$ & 127.6 & 132.5 \\
\hline Thick stripes & & & 3791 & $147.3 \pm 0.91$ & 145.5 & 149.1 & $130.1 \pm 1.23$ & 127.4 & 132.1 \\
\hline Pale $_{\text {lat }}$ stripes & & & 7383 & $167.9 \pm 0.61$ & 166.7 & 169.1 & $137.5 \pm 1.73$ & 134.1 & 140.9 \\
\hline Pale $_{\text {med }}$ stripes & & & 7325 & $182.8 \pm 0.51$ & 181.8 & 183.8 & $133.1 \pm 1.29$ & 130.6 & 135.7 \\
\hline Blob radius (all stripes) & & & $2675^{a}$ & & & & $131.0 \pm 0.78$ & 129.5 & 132.5 \\
\hline
\end{tabular}

${ }^{a} N=$ numbers of markers placed along blob borders to define blob radius (Fig. 2D).

tionally distinct pale stripe types, those located medially ( pale $_{\text {med }}$ ) and those located laterally ( pale $_{\text {lat }}$ ) to thick stripes (Roe and Ts'o, 1995; Shipp and Zeki, 2002; Xu et al., 2004), we have performed separate quantitative analyses for the two pale stripe types.
Injections confined to either type of V2 pale stripes $(n=9,4$ in pale $_{\text {lat }}, 5$ in pale $e_{\text {med }}$ ) produced labeled cells primarily in layer $2 / 3$ within the interblobs of V1. However, there was a difference in both the tangential and laminar distribution of label between the 

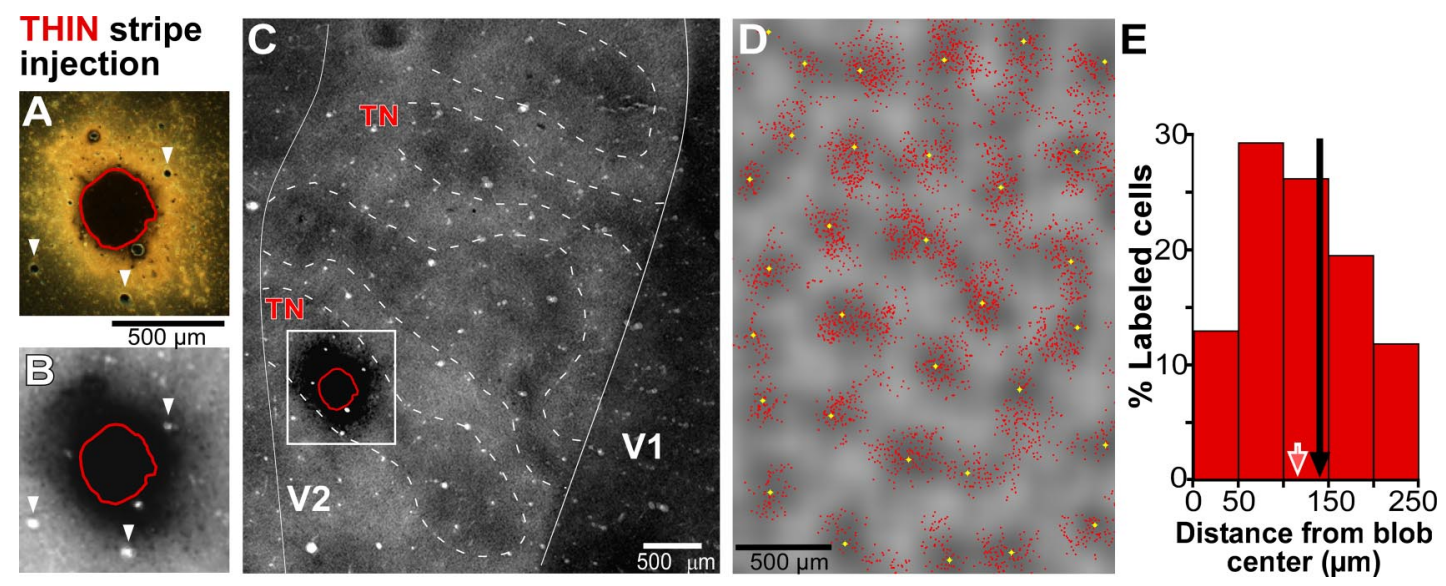

Figure 3. V2 thin stripes receive projections from C 0 blobs (case 250). $A$, Dark-field image of a CTBg injection site. The tracer uptake zone in $A-C$ is outlined in red. The arrowheads point at the same blood vessels as in $\boldsymbol{B}$. Scale bar under $\boldsymbol{A}$ applies to both $\boldsymbol{A}$ and $\boldsymbol{B}$. $\boldsymbol{B}$, Same section and same field of view as in $\boldsymbol{A}$, but shown under bright-field illumination. This section was stained for $C 0$ and CTBg. C, Lower power, and wider field of view of the same section as in $\boldsymbol{A}$ and $\boldsymbol{B}$, viewed in bright field, showing alternating thin (TN), pale, and thick $\mathrm{CO}$ stripes in V2 (dashed contours outline the dark $\mathrm{CO}$ stripes). Solid white contours, Anterior and posterior borders of $\mathrm{V} 2$. The area inside the white box is shown at higher power in $\boldsymbol{B}$. Here, and in Figures $4 C, 5 C, 6 C$, and $8, C$ and $H$, medial is to the top, and posterior to the right. $\boldsymbol{D}$, Plots of layer $2 / 3 \mathrm{~V} 1$ cells (red dots) retrogradely labeled from the tracer injection in $\boldsymbol{A}$-C are shown superimposed to a filtered image of the $C 0 \mathrm{blobs}$. The yellow stars mark the blob centers. $\boldsymbol{E}$, Distribution of the distance of the labeled cells to the nearest blob center. Red arrow, Median cell distance; black arrow, median blob radius for this case. The same conventions are used in Figures $4-6$ and 8.

pale $_{\text {med }}$ and pale $e_{\text {lat }}$ injection cases. In the tangential domain, after pale med $_{\text {ma }}$ stripe injections, the $\mathrm{V} 1$ label in layer 2/3 was more restricted to the middle of the interblobs than after pale lat injections. This is apparent when comparing the pale ${ }_{\text {med }}$ injection case (282-1) shown in Figure 4, with the two pale lat $_{\text {injection cases }(260-\mathrm{m} \text { and }}$ 274-m) shown in green in Figure 8. Compared with these pale lat injection cases, the pale $_{\text {med }}$ injection case had a greater median cell distance to the nearest blob center $(212 \mu \mathrm{m}$ in case $282-1$ vs $169 \mu \mathrm{m}$ in case $260-\mathrm{m}$, and $175 \mu \mathrm{m}$ in case $274-\mathrm{m}$ ), larger percentage of labeled cells outside the median blob radius (91 vs 72 and $75 \%$ ), and larger percentage (60 vs 29 and $31 \%$ ) of labeled cells in the middle of the interblobs (200-250 $\mu \mathrm{m}$ from blob centers) (Table 1).

Higher density of labeled cells in the middle of the interblobs after pale med $_{\text {as }}$ opposed to pale lat $_{\text {injections was observed }}$ for all pale stripe injections (we quantified four pale $_{\text {med }}$ and four pale lat $_{\text {injection }}$ cases) (Table 1). In all cases, sparser label was also present in the blobs; however,

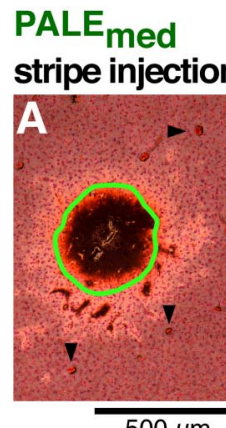

$500 \mu \mathrm{m}$
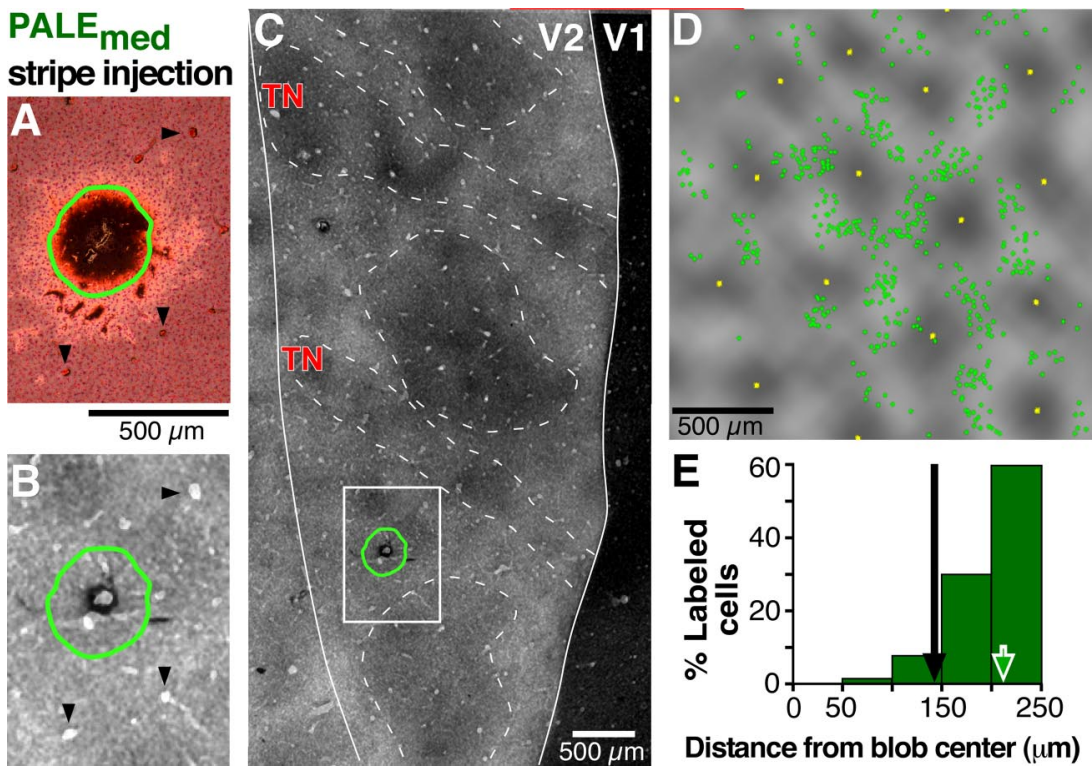

Figure 4. V2 pale stripes receive projections from C 0 interblobs (case 282-I). $A$, Dark-field image of a CTBg injection site (uptake zone outlined in green). $\boldsymbol{B}$, The uptake zone outline from $\boldsymbol{A}$ is shown superimposed to a bright-field image of a C0-stained section adjacent to that in $\boldsymbol{A}$. $\boldsymbol{C}$, Lower-power image and wider field of view of the same section as in $\boldsymbol{B}$ showing the $\mathrm{C} 0$ stripes in V2. D, Plots of layer 2/3 V1 cells ( $g r e e n$ dots) labeled from the tracer injection in $\boldsymbol{A}-\boldsymbol{C}$ are superimposed to a filtered image of the $C O$ blobs. $E$, Distribution of the distance of the labeled cells to the nearest blob center. Green arrow, Median cell distance. unlike label resulting from pale lat $_{\text {injec- }}$ tions, label resulting from pale ${ }_{\text {med }}$ injections avoided the centers of blobs (Figs. $4 E, 8 E$, J; Table 1). In Population statistics (see below), we show that this difference between the pale stripes, albeit small, is statistically significant.

Differences between pale ${ }_{\text {med }}$ and pale lat $_{\text {at }}$ stripe injections were also observed in the laminar distribution of resulting V1 label. Specifically, both pale stripe types received projections predominantly from layer $2 / 3$, and sparser (but significant) projections from layer $4 \mathrm{~A}$. However, only pale ${ }_{\text {lat }}$ stripes received an additional small projection from layers $4 \mathrm{~B}$ and $5 / 6$. Labeled cells in layers $4 \mathrm{~A}$ and $4 \mathrm{~B}$ were in vertical register with those in layer $2 / 3$, whereas cells in layer $5 / 6$ showed no clear relationship with blobs or interblobs. The layer $2 / 3$ population data on the tangential distribution of V1 label after pale lat $_{\text {(light green bars) and pale }}$ (dark green bars) tracer injections are shown in Figure 7, $A$ and $B$, and in Table 1; the layer $4 \mathrm{~B}$ population data are shown in Figure 7C. Quantitative data on the laminar distribution of V1 label are presented below in Results.

These results from tracer injections into pale stripes confirm and extend previous observations in macaque (Xiao and Felleman, 2004; Sincich et al., 2007), by demonstrating, for the first pale stripes. time, two separate pathways from the V1 interblobs to the two 


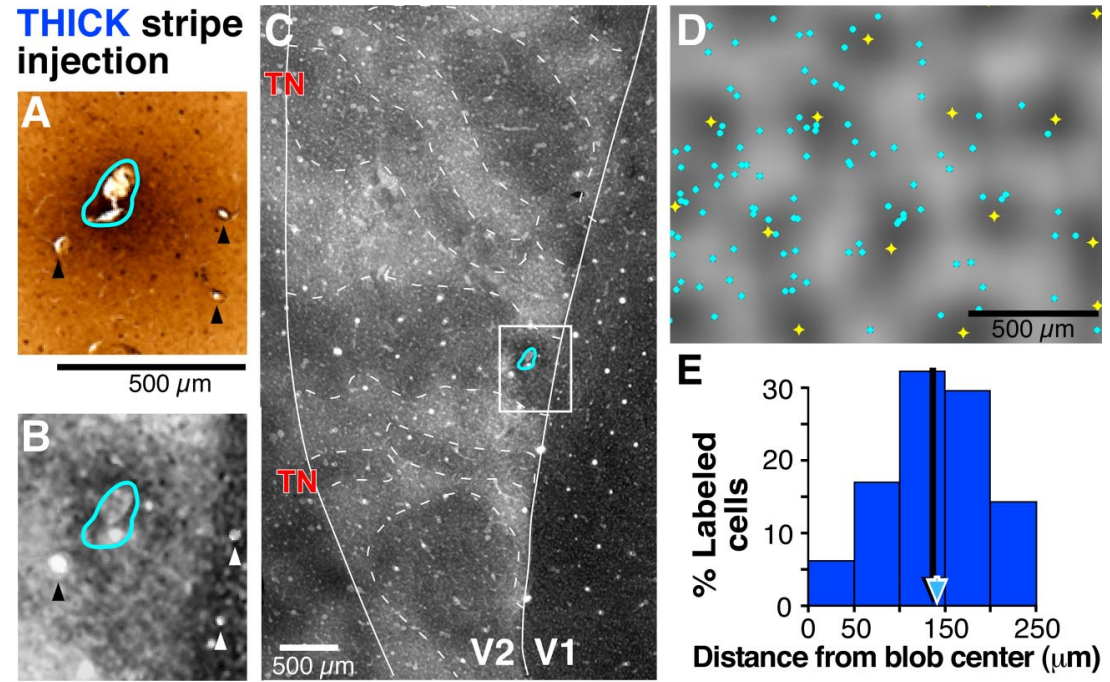

Figure 5. V2 thick stripes receive projections from blob/interblob border regions (case 274LH-I). $\boldsymbol{A}$, Bright-field image of a FR injection site (blue, uptake zone outline). $\boldsymbol{B}$, The uptake zone outline from $\boldsymbol{A}$ is shown superimposed to a bright-field image of an adjacent $C 0$-stained section. $\boldsymbol{C}$, Lower-power image and wider field of view, of the same section as in $\boldsymbol{B}$ showing the $\mathrm{C} O$ stripes in V2. D, Plots of layer 2/3 V1 cells (blue dots) labeled from the tracer injection in $\boldsymbol{A}-\boldsymbol{C}$ are superimposed to a filtered image of the $\mathrm{C} O$ blobs. $\boldsymbol{E}$, Distribution of the distance of the labeled cells to the nearest blob center. Blue arrow, Median cell distance.

\section{Thick stripe injections}

Injections confined to $\mathrm{V} 2$ thick stripes $(n=9)$ produced labeled cells primarily in layers $2 / 3$ and $4 \mathrm{~B}$ within the "blob/interblob (B/I) border region" (i.e., within about $\pm 50 \mu \mathrm{m}$ of the blob borders). A typical case (274LH-l) is shown in Figure 5. Here, an injection of FR centered in a thick stripe (Fig. $5 A-C$ ) produced labeled cells preferentially near the blob borders, and sparse label in the center of the blobs and interblobs (Fig. 5D). In layer 2/3, the median blob radius for this case $(136 \mu \mathrm{m})$ essentially coincided with the median cell distance to the nearest blob center $(141 \mu \mathrm{m})$, and $60 \%$ of cells were located within $\pm 50 \mu \mathrm{m}$ of this radius. Outside the $\mathrm{B} / \mathrm{I}$ border region, the majority of labeled cells $(\sim 26 \%)$ were located within $100 \mu \mathrm{m}$ of the blob center. Sparser, but significant, label was also present in layer $4 \mathrm{~A}$, and very few labeled cells in layers 5/6. Label in layers $4 \mathrm{~A}$ and $4 \mathrm{~B}$, but not in $5 / 6$, was also preferentially located in the $\mathrm{B} / \mathrm{I}$ border region. The other thick stripe injection cases (two of which are shown in Figs. 6 and $8 A-E$, respectively) showed similar results (quantification was performed for six cases) (Table 1). The population data for layer $2 / 3$ and $4 \mathrm{~B}$ label resulting from thick stripe injections are shown in Figure $7 A-C$ (blue bars), respectively.

Because cell label inside the CO blobs has typically been associated with tracer injections into thin stripes, it was important to assure that in our analysis of thick stripe injections we included only data from definitive thick stripes. We are confident that our results were not attributable to the tracer injection sites having involved both thick and thin stripes, as we only analyzed injection cases that were clearly confined to a single thick stripe (as demonstrated in Figs. 5C, 6C, and 8C). In addition, stripes were classified as thick only if they met the following two requirements. First, they appeared thicker in $\mathrm{CO}$ staining and were sandwiched between two thinner dark stripes (Figs. 5C, 6C, 8C). Second, tracer injections in these stripes produced label in area MT (Fig. $6 C$ ), which in other primate species is known to be connected with the V2 thick, but not thin stripes [e.g., in macaque (DeYoe and Van Essen, 1985; Shipp and Zeki, 1985)]. In addition, using intrinsic signal optical imaging, we confirmed in two cases (M and S) (Table 1) that the tracer-injected thick stripes coincided with regions having an orientation map (one such case, $M$, is shown in Fig. 6). Optical imaging studies of area V2 in macaque (Malach et al., 1994; Lu and Roe, 2008) and New World primates (Xu et al., 2004), including marmosets (Roe et al., 2005), have previously demonstrated orientation maps in the thick, but not thin, CO stripes (Vanduffel et al., 2002). Like other thick stripe injections, V1 label resulting from thick stripe injections in these two optically imaged cases showed a similar preferential distribution within the $\mathrm{B} / \mathrm{I}$ border region (Fig. $6 D, I$, Table 1 ). For example, in the case shown in Figure 6 , the median cell distance from the nearest blob center $(129 \mu \mathrm{m})$ coincided with the median blob radius $(128 \mu \mathrm{m})$.

In conclusion, we are confident that our tracer injections into $\mathrm{CO}$ stripes that were classified as thick indeed involved V2 stripes corresponding histochemically, anatomically, and physiologically to the thick stripes of other Old and New World primates.

\section{Population statistics}

Figure $7 A$ and Table 1 summarize our population data on the tangential distribution of layer $2 / 3 \mathrm{~V} 1$ cells projecting to each V2 stripe type. The distance measurements of all labeled cells were pooled into four groups based on the stripe location of the respective tracer injections. A fifth group consisted of distance measurements for all the markers placed along the blob borders used to determine the blob radius (Fig. $2 D$ ), pooled across all cases. Figure $7 B$ and Table 2 show the mean distance of labeled cells to the nearest blob center, and the 95\% confidence interval, for each single case and for each stripe group, as well as the mean blob radius for each case and for the whole population. Inspection of Figure $7 B$ reveals a systematic tangential organization of V1 outputs to different stripe types: those to the thin stripes arising closest to the blob center, and those to the thick and pale stripes arising progressively farther from blob centers. Specifically, the mean cell distance to the nearest blob center for the population of thin $(118 \mu \mathrm{m})$ and thick $(147 \mu \mathrm{m})$ stripe injections fell just inside and just outside, respectively, of the mean blob radius for the population $(131 \mu \mathrm{m})$. Instead, the mean cell distance for the pale stripes fell well outside the mean blob radius, with the population mean for the pale ${ }_{\text {med }}$ stripes $(183 \mu \mathrm{m})$ falling closer to the middle of the interblob than the population mean for the pale lat $_{\text {stripes }}(168 \mu \mathrm{m})$. The mean distance for each stripe group was highly significantly different from the mean distance of each other stripe group, and from the mean blob radius for the population ( $p=0.000$, one-way ANOVA contrasts). More importantly, the $95 \%$ confidence interval for each group was very small $(\sim 2-3 \mu \mathrm{m})$ (Table 2, Fig. $7 B)$ and showed no overlap with that of any other group. Instead, within each group, the mean cell distance was more uniformly distributed, and the confidence intervals generally overlapped. However, statistically significant differences were found between the extremes within a group (the asterisks in Fig. $7 B$ mark the cases that were significantly different from at least one other case within the same group), but gen- 


\section{THICK stripe injection}
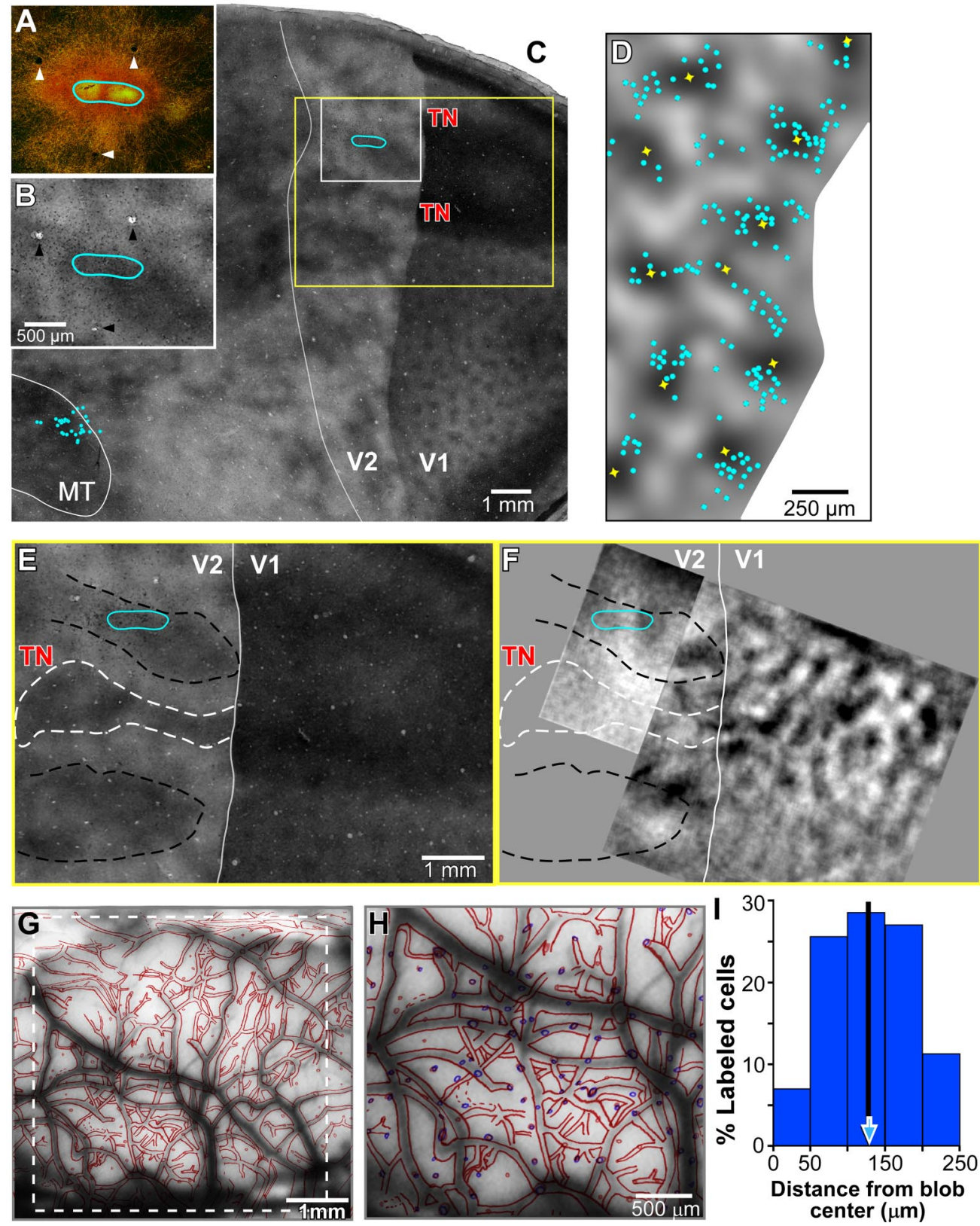

Figure 6. V2 thick stripes receiving projections from B/l border regions are connected with MT and coincide with optically imaged V2 regions having an orientation map (case M). $A$, Dark-field image of a (TB injection site (blue, uptake zone outline). $\boldsymbol{B}$, The uptake zone outline from $\boldsymbol{A}$ is shown superimposed to a bright-field image of an adjacent $(0$-stained section. C, Lower-power image and wider field of view of the same section as in $\boldsymbol{B}$, showing the $\mathrm{CO}$ stripes in V2, the CO blobs and interblobs in V1, and extrastriate cortical areas rostral to V2, including portions of area MT. Blue dots in MT, Plots of cells retrogradely labeled from the CTB injection shown in $A-C$. The area inside the yellow box corresponds to the optically imaged region $(\boldsymbol{F})$ and is shown at higher magnification in $\boldsymbol{E}$. $\boldsymbol{D}$, Plots of labeled $\mathrm{V} 1$ cells (blue dots) in layers $2 / 3$ resulting from the CTB injection in $\boldsymbol{A}-\boldsymbol{C}$ are shown superimposed to a filtered image of the $\mathrm{CO}$ blobs. $\boldsymbol{E}$, Higher magnification of the region inside the yellow box in $\boldsymbol{C}$. The solid white contour delineates the V1-V2 border; dashed white and black contours outline a thin and two thick stripes, respectively; blue contour, outline of the CTB uptake zone from $\boldsymbol{A}$. $\boldsymbol{F}$, The outlines of the V2 CO stripes and of the CTB uptake zone, and the position of the V1-V2 border from $\boldsymbol{E}$ are superimposed to a differential orientation map, generated by subtracting single condition maps in response to stimuli of 90 and $0^{\circ}$ orientation. Orientation responsive domains are seen in both V2 thick and pale, but not thin, stripes, as well as in V1. Note that the CTB injection site is in a V2 stripe containing an orientation map. G, Overlay of CO-stained sections with the optical maps was achieved by aligning the drawing of the surface vasculature from the most superficial histological section (red outlines) to the reference image of the vasculature taken during optical imaging. Dashed box, Imaged region. $\boldsymbol{H}$, Higher magnification of part of the image shown in $\mathbf{G}$, demonstrating the high-precision alignment that was achieved. Blue ovals, Radial blood vessels from a deeper tissue section aligned to the radial vessels (red ovals) in the most superficial section. $I$, Distribution of the distance of the V1-labeled cells to the nearest blob center. Blue arrow, Median cell distance.

erally not between extremes across groups (with the exception of case M). The latter observation suggests additional heterogeneity in the spatial organization of V1 outputs to the same stripe type. Alternatively, some injections may have simply been more restricted to a stripe center than other injections, although visual inspection of our tracer injection sites did not appear to support this interpretation.

The tangential distribution of the population of layer $4 \mathrm{~B}$ cells labeled by injections in different $\mathrm{V} 2$ stripe types resembled that of the layer $2 / 3$ population (Fig. $7 C$ ). There was no statistically sig- 
A

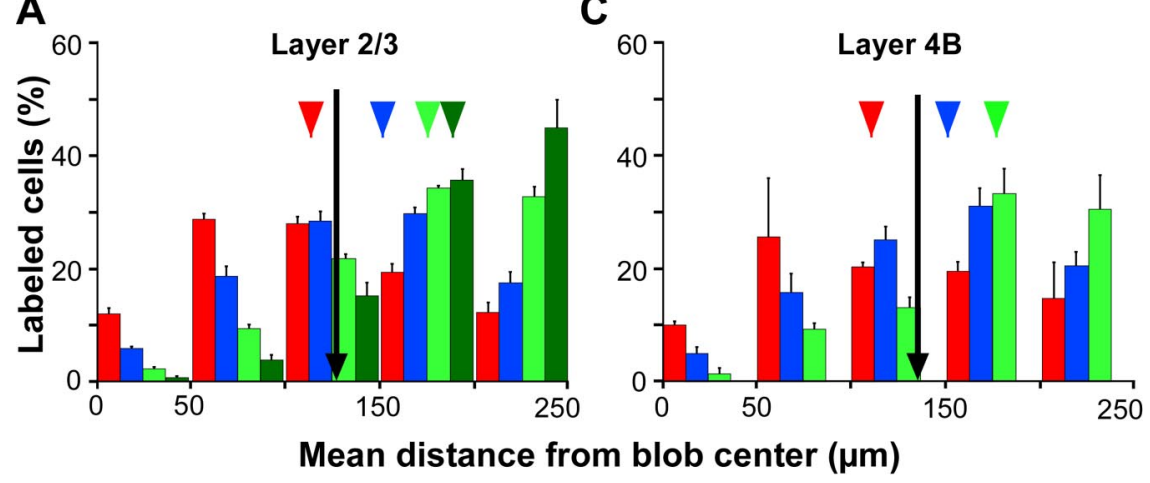

B

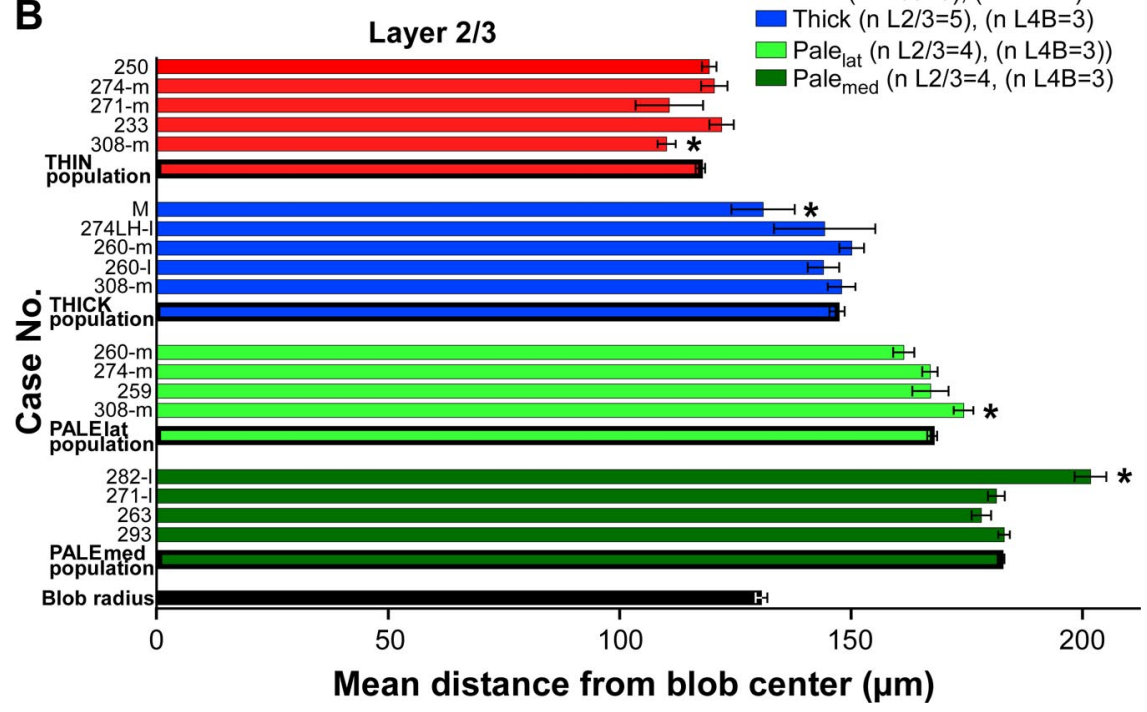

Figure 7. Tangential distribution of V1 cells projecting to different V2 stripes: population data. $\boldsymbol{A}-\boldsymbol{C}$, Distribution of mean distances to the nearest blob center of the population of labeled cells in layers $2 / 3(\boldsymbol{A})$ and $4 B(C)$, grouped by injected stripe type. The " $n$ " in the legend indicates the number of cases in each stripe group for $\boldsymbol{A}$ and $\boldsymbol{B}$, and $\boldsymbol{C}$, respectively. Black arrow, Median blob radius ( $127.2 \mu \mathrm{m}$ in $\boldsymbol{A} ; 135.3 \mu \mathrm{m}$ in $\boldsymbol{B}$ ) for all cases used in each histogram ( $n=11$ in $\boldsymbol{A} ; n=8$ in $\boldsymbol{C}$ ). Arrowheads, Medians for each respective stripe group (for layer $2 / 3$ median values, see Table 1 ). Median values in $\boldsymbol{B}$ are as follows: $108.5 \mu \mathrm{m}$ (thin), $148.1 \mu \mathrm{m}$ (thick), $176.4 \mu \mathrm{m}$ (pale ${ }_{\text {lat }}$ ); there were no labeled cells in layer $4 B$ after pale med injections. $\boldsymbol{B}$, Mean cell distance to the nearest blob center for each case (case number is indicated on the $y$-axis) used in the histogram in $\boldsymbol{A}$, and for each stripe group (bars with thick outline). Black bar, Mean blob radius for the population. Error bars are $95 \%$ confidence intervals for the mean. The asterisks mark cases that were significantly different from at least one other case within the same stripe group.

nificant difference within each stripe group between the labeled cells mean distance in layers $2 / 3$ versus $4 \mathrm{~B}(p=0.568,0.447$, and 0.785 for the thin, thick, and pale ${ }_{\text {lat }}$ stripe groups, respectively; one-way ANOVA contrasts). This indicates columnar arrangement of $\mathrm{V} 1$ cells in layers $2 / 3$ and $4 \mathrm{~B}$ projecting to the same $\mathrm{V} 2$ stripe type.

\section{Paired tracer injections: double-labeling studies}

The results in Figure $7 B$ suggest three segregated pathways from V1 to the thin, thick, and pale stripes, and support our hypothesis that the interblob region is partitioned into two specialized compartments projecting preferentially to the pale or thick stripes. However, results in Figure $7 A$ also indicate lack of strict segregation, as V1 output cells to each stripe type could reside at any distance from blob centers (i.e., both inside and outside blobs). To determine whether different stripe types receive projections from distinct V1 neuronal populations, we performed double-labeling studies. Paired injections of two different tracers were made into two adjacent stripe types ( $n=6$ injection pairs) or in the same stripe type $(n=3$ injection pairs). The area of overlap between the two resulting labeled fields was measured, and the number of double-labeled cells was counted within this area (Table 3) (see Materials and Methods). In one animal (case 308-m), five different tracer injections involved a full stripe cycle: two injections in the same thick stripe, two in the nearest thin stripe, and one in the intervening pale $e_{\text {lat }}$ stripe (injection sites for this case are shown in supplemental Fig. 3, available at www.jneurosci.org as supplemental material). In three additional animals, pairs of different tracer injections involved either adjacent thick and pale lat stripes (case 260-m) (Fig. 8A-C), or adja-

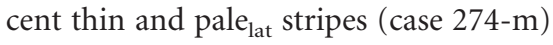
(Fig. $8 F-H$ ), or the same pale med $_{\text {stripe }}$ (case 293) (supplemental Fig. 4, available at www.jneurosci.org as supplemental material). Figure $8 D$ shows the neuronal labeled fields produced by the CTBg (blue outline) and $\mathrm{CTB}_{488}$ (green outline)

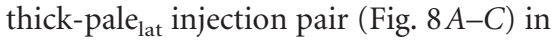
case $260-\mathrm{m}$. The neuronal labeled fields resulting from these two injections occupied mostly the same $\mathrm{V} 1$ region $(78 \%$ of the $\mathrm{CTB}_{488}$-labeled field overlapped with the CTBg-labeled field) (Table 3). Within this overlap region, the two cell populations appeared to retain the characteristic distance from the nearest blob center that we had observed after single stripe injections (i.e., cells labeled from the pale stripe injection lay closer to the middle of the interblobs than those labeled from the thick stripe injection) (Fig. $8 D, E$, Table 1 ). In this case, however, the two distributions showed somewhat more overlap than seen after other thick and pale stripe injections listed in Table 1. Despite the greater overlap in the distributions of cell distances in this case, of 1910 total labeled cells (760 CTBg-labeled, $1034 \mathrm{CTB}_{488}$-labeled, and 116 double labeled for both tracers), only $6 \%$ were double labeled (Fig. $8 D$, purple dots). To compare our results with those of a previous similar study in macaque (Sincich and Horton, 2002), and because the number of cells labeled by each tracer differed, we also determined the percentage of double-labeled cells out of the total number of cells labeled by only one tracer (the one producing the smallest number of labeled cells) (Table 3, right column). Using this criterion, in case $260-\mathrm{m}$ we found that, of 876 CTBg-labeled cells, $13 \%$ were double labeled for both CTBg and $\mathrm{CTB}_{488}$. The other case of injection pairs in adjacent thick and pale ${ }_{\text {lat }}$ stripes (case 308-m) produced a similar percentage of double-labeled cells, despite the fact that the two injection sites were farther apart in V2, and the resulting neuronal fields labeled by each tracer were less overlapped (Table 3 ). These results demonstrate mostly segregated populations of output neurons from V1 to the V2 thick and pale stripes.

Paired injections of different tracers in adjacent thin and pale $e_{\text {lat }}$ stripes ( $n=3$ injection pairs) (Table 3 ) also demonstrated segre- 


\section{THICK and PALE ${ }_{\text {lat }}$ stripe injections}
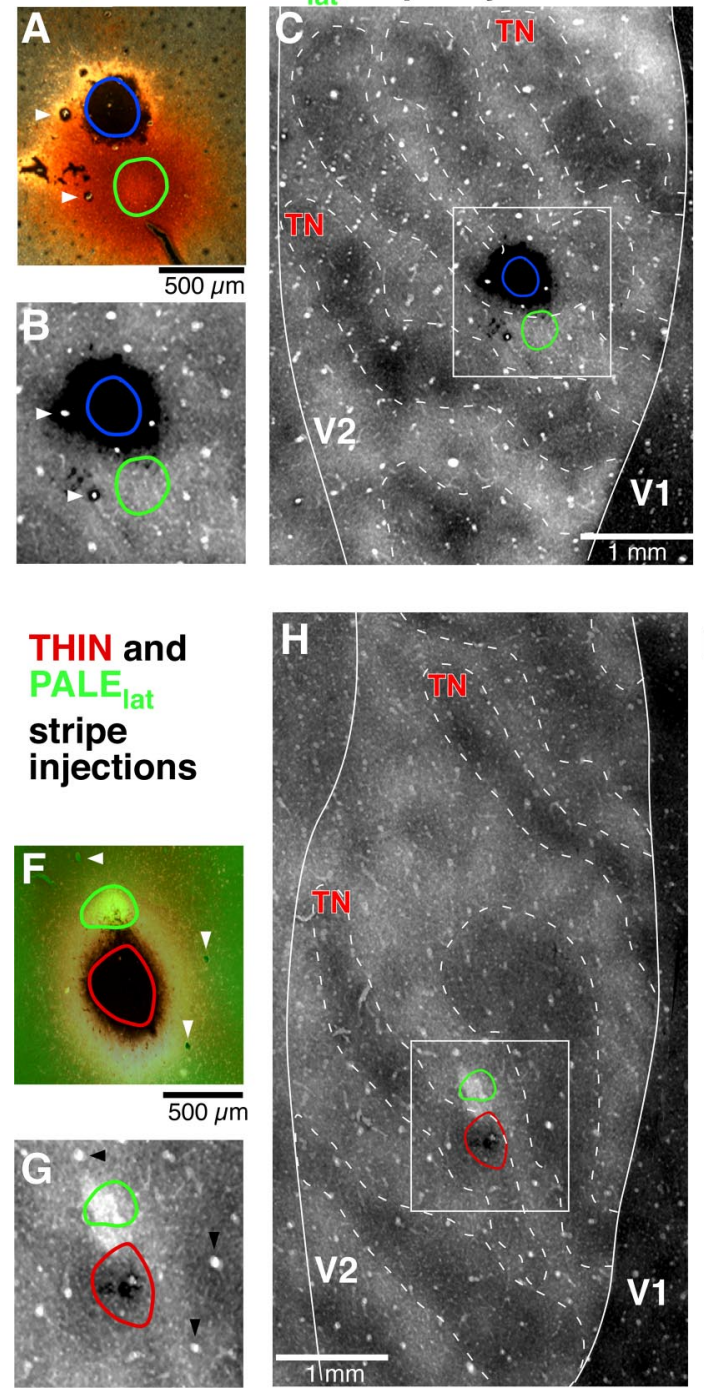

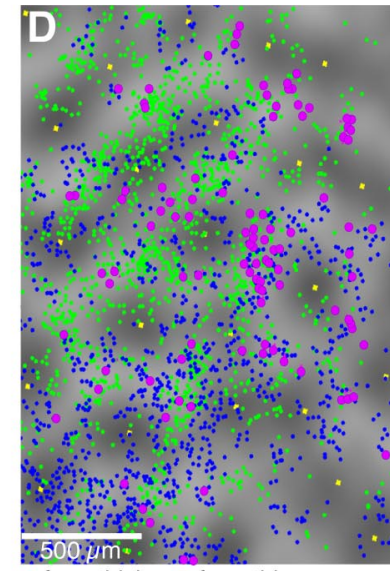

from thick from thin
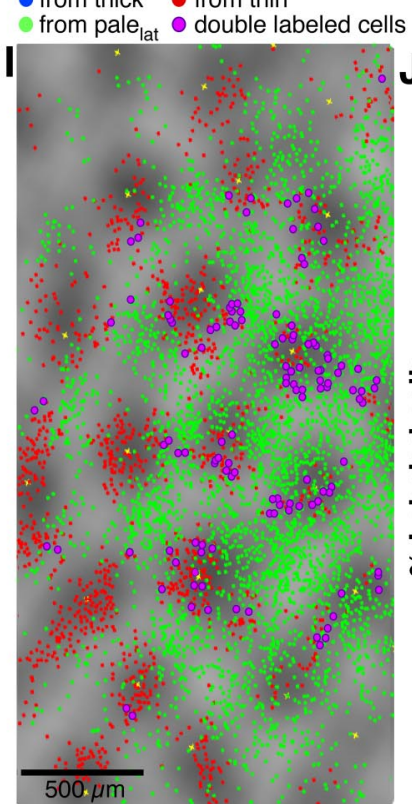

E
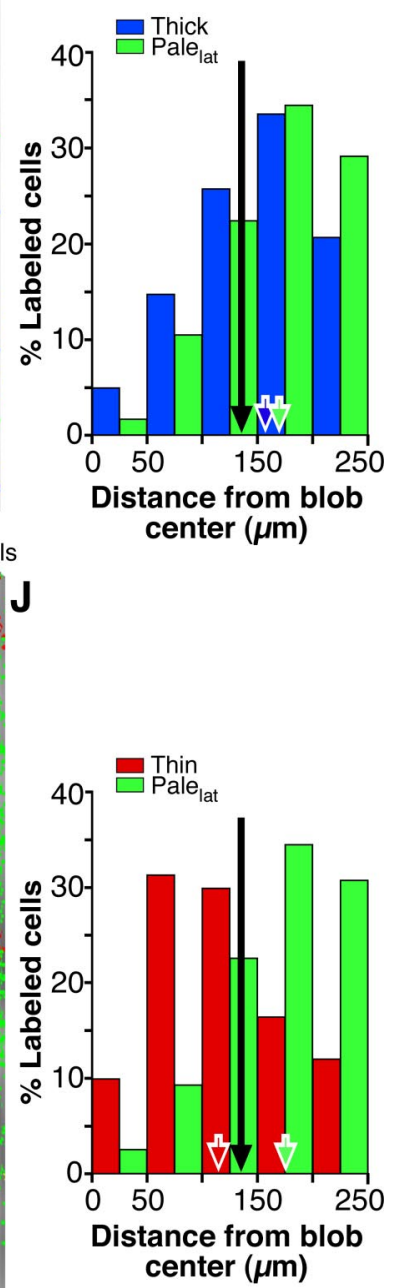

Figure 8. Paired tracer injections in adjacent stripe types demonstrate segregated neuronal populations projecting from V1 to V2. A, Case 260-m. Dark-field image of a CTBg injection site (outlined in blue) next to a $\mathrm{CTB}_{488}$ injection site (outlined in green). $\boldsymbol{B}$, The outlines of the tracer uptake zones are superimposed to the bright-field image of an adjacent section stained for $\mathrm{CO}$ and silver-reacted to reveal CTBg (black deposit). C, Lower power image, and wider field of view of the same section as in $\boldsymbol{B}$ showing the V2 CO stripes. D, Plots of V1 layer $2 / 3 \mathrm{CTBg}$ (blue)- and $\mathrm{CTB}_{488}$ (green)-labeled cells, resulting from the injections in $\boldsymbol{A}-\boldsymbol{C}$, are superimposed to a filtered image of $C 0$ blobs. Purple dots, Double-labeled cells. $E$, Tangential distributions of the distance of $\mathrm{CTBg}$ (blue)- and $\mathrm{CTB}_{488}$ (green)-labeled cells from the nearest blob center. Green and blue arrows, Medians of each respective neuronal population. $F$, Case 274-m. Images of a $\mathrm{CTB}_{488}$ injection (outlined in green), viewed under fluorescence microscopy, and of a CTBg injection (outlined in red), viewed in dark field, were overlaid and merged. In $\boldsymbol{G}$ and $\boldsymbol{H}$, the outlines of the tracer uptake zones from $\boldsymbol{A}$ are superimposed to the image of an adjacent $\mathrm{C} 0$-stained section, shown at two different magnifications and field of views in $\boldsymbol{G}$ and $\boldsymbol{H}$. $\boldsymbol{I}$, Plots of V1 layer 2/3 CTBg (red)- and $\mathrm{CTB}_{488}$ (green)-labeled cells, and of double-labeled cells (purple), resulting from the injections in $\boldsymbol{F}$ - $\boldsymbol{H}$, are superimposed to a filtered image of $\mathrm{CO}$ blobs. J, Tangential distributions of the distance of the labeled cells to the nearest blob center for each labeled V1 neuronal population. Red and green arrows, Medians of each respective neuronal population.

gated pathways from V1 to these two V2 stripe types. One example case $(274-\mathrm{m})$ is shown in Figure $8 \mathrm{~F}-J$. In this case, the two injection sites lay near each other, on either side of a thin-pale stripe border (Fig. $8 \mathrm{~F}-\mathrm{H}$ ) and resulted in $89 \%$ overlap between the two single-labeled fields (Table 3). Yet, within the overlap region, cells labeled from the thin stripe injection were found preferentially in the blobs, whereas those labeled from the pale stripe injection lay preferentially in the middle of the interblobs (Fig. $8 I, J$ ), and only $3 \%$ of the total labeled V1 cells (or $13 \%$ of CTBg-labeled cells) were double-labeled (Fig. 8I, purple dots; Table 3). The other two cases of injection pairs in adjacent thin and pale stripes produced similar percentage of double-labeled cells, despite significant differences in the proximity of the two injection sites and resulting overlap in the labeled fields (Table 3).
In contrast, control paired injections delivered to the same stripe type $(n=3)$ (Table 3 ) resulted in a substantially higher percentage of double-labeled cells (i.e., up to $20 \%$ of the total number of labeled cells, or up to $83 \%$ of cells labeled with only one tracer), depending on the interinjection distance. For the population of paired injections in the same stripe type, the percentage of double-labeled cells was highly correlated with both interinjection distance ( $r=-0.988$; Pearson's correlation) and percentage overlap between labeled fields $(r=0.997)$ (Fig. $9 A, B$, squares). This indicates that, within the overlap region, a large proportion of cells projected to both injection sites and that this proportion increased with increasing overlap area. The latter, however, decreased with increasing distance between the injection sites ( $r=-0.997)$ (Fig. 9C, squares), as predicted by the 
Table 3. Number of double-labeled cells in V1 layer 2/3

\begin{tabular}{|c|c|c|c|c|c|c|c|c|c|c|}
\hline & & & & & $\begin{array}{l}\text { No. of } \\
\text { single-lab }\end{array}$ & & & $\begin{array}{l}\text { \% Double- } \\
\text { labeled cells }\end{array}$ & & \\
\hline CO stripes and & acers injected & & & & cells & & No. of & & $\%$ of smallest & \\
\hline $\begin{array}{l}\text { Stripe } 1 \\
\text { Tracer } 1 \\
\end{array}$ & $\begin{array}{l}\text { Stripe } 2 \\
\text { Tracer } 2\end{array}$ & Case no. & $\begin{array}{l}\text { Interinjection } \\
\text { distance }(\mu \mathrm{m})^{a}\end{array}$ & $\begin{array}{l}\text { Label } \\
\text { overlap }(\%)^{b}\end{array}$ & Tracer 1 & Tracer 2 & $\begin{array}{l}\text { double-labeled } \\
\text { cells }\end{array}$ & $\begin{array}{l}\% \text { of total } \\
\text { labeled cells }\end{array}$ & $\begin{array}{l}\text { no. of cells labeled } \\
\text { with one tracer }\end{array}$ & Figure \\
\hline Thick CTBg & Pale $_{\text {lat }}$ CTB 488 & $260-m$ & -104 & 78.2 & 760 & 1034 & 116 & 6.1 & 13.2 & Fig. $8 A-D$ \\
\hline Thick CTB 488 & Pale $_{\text {lat }}$ CTB 555 & $308-m$ & 288 & 60.6 & 986 & 1351 & 193 & 7.6 & 16.4 & Supplemental Fig. $3^{e}$ \\
\hline Thin CTBg & Pale $_{\text {lat }}$ CTB 488 & $274-m$ & -184 & 89 & 931 & 3635 & 139 & 3.0 & 13.0 & Fig. $8 \mathrm{~F}-\mathrm{I}$ \\
\hline Thin CTB 647 & Pale $_{\text {lat }}$ CTB 555 & $308-m$ & 853 & 61 & 2586 & 1194 & 173 & 4.4 & 12.7 & Supplemental Fig. $3^{e}$ \\
\hline Thin DY & Pale $_{\text {lat }}$ CTB 555 & $308-m$ & 120 & 93.6 & 2199 & 1006 & 96 & 2.9 & 8.7 & Supplemental Fig. $3^{e}$ \\
\hline Thick CTB 488 & Thick CTBg & $308-m$ & -127 & 76.3 & 327 & 107 & 97 & 18.3 & 47.5 & Supplemental Fig. $3^{e}$ \\
\hline Pale $_{\text {med }}$ DY & Pale $_{\text {med }}$ CTB 555 & 293 & -455 & 94.6 & 4777 & 255 & 1255 & 20.0 & 83.1 & Supplemental Figs. $4,5^{e}$ \\
\hline Thin DY & Thin CTB 647 & $308-m$ & 318 & 57.4 & 972 & 1448 & 235 & 8.9 & 19.5 & Supplemental Fig. $3^{e}$ \\
\hline Thick CTB 488 & Thin DY & $308-m$ & 588 & 55.9 & 666 & 736 & 11 & 0.8 & 1.6 & Supplemental Fig. $3^{e}$ \\
\hline
\end{tabular}

${ }^{a}$ Distance between the lateral edge of medial-most injection site and medial edge of lateral-most injection site, measured across C 0 stripes (negative values indicate that the two injections partially overlap in the mediolateral plane, albeit not in the anteroposterior plane).

${ }^{b}$ Area of overlap of the two labels/smallest area of single labeled field $\times 100$.

'Calculated as follows: no. double-labeled cells*100/(no. tracer 1-labeled cells + no. tracer 2-labeled cells + no. double-labeled cells).

${ }^{d}$ Calculated as follows: no. double-labeled cells*100/(smallest no. of cells labeled with a single tracer + no. double-labeled cells).

${ }^{e}$ Available at www.jneurosci.org as supplemental material.

known retinotopic organization of feedforward V1-to-V2 projections (Salin and Bullier, 1995). In contrast, this was not the case for our control cases (i.e., paired injections in the same stripe types). For these injection cases, despite the fact that closer injection sites produced larger overlap between the single-labeled fields $(r=-0.77)$ (Fig. 9C, dots), there was no correlation between percentage of double-labeled cells and either percentage of label overlap $(r=0.166)$, or interinjection distance $(r=-0.315)$ (Fig. 9A, $B$, dots). This indicates that, even within mostly overlapped labeled fields (up to $94 \%$ overlap), individual cells projected to only one or the other stripe type. Based on the results above on the tangential distribution of label produced by injections in different stripe types, we know this resulted from the fact that, within the overlap area, cells projecting to different stripe types occupy mostly different CO compartments in V1. In contrast, within the overlap area, cells projecting to the same stripe type occupy mostly the same V1 compartments. In supplemental Figures 4 and 5 (available at www.jneurosci.org as supplemental material), we show the injection sites and resulting label, respectively, for one control case in which both injections were located

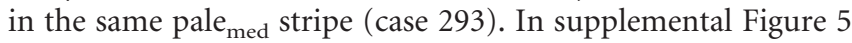
(available at www.jneurosci.org as supplemental material), note the precise overlap of label produced by the two tracer injections.

\section{Laminar distribution of $\mathrm{V} 1$ cells projecting to $\mathrm{V} 2$}

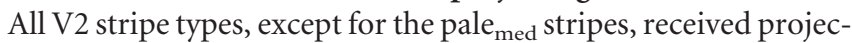
tions from V1 layers 2/3, 4A, and 4B (Fig. 10). Layer 4A sent significant projections to thick and both pale stripes, and a sparse projection to thin stripes. Layers $5 / 6$ sent small projections to thin and pale lat $_{\text {stripes, and little or no projections to thick and pale }}$ med stripes, respectively (supplemental Table 1, available at www. jneurosci.org as supplemental material). Pale $_{\text {med }}$ stripes received projections exclusively from layers $2 / 3$ and $4 \mathrm{~A}$ (Fig. $10 I, K, L$ ). We quantified the relative contribution of $\mathrm{V} 1$ layers $2 / 3$ and $4 \mathrm{~B}$ to each pathway (Table 4). Because layer $4 \mathrm{~A}$ is very thin, and because in many cases only one in every third section was reacted to reveal any injected tracer, we often had only a single section per case showing any label in $4 \mathrm{~A}$. Therefore, we did not quantify the label in $4 \mathrm{~A}$, as we could have easily missed the section(s) with the densest label in this layer. In a smaller number of cases, we also quantified the sparse label in layers 5/6 (supplemental Table 1, available at www.jneurosci.org as supplemental material).

Laminar boundaries were determined using CO or Nissl staining on the same sections in which labeled cells were plotted. We counted labeled cells on a full series of sections through layers $2 / 3$ and $4 \mathrm{~B}$, and determined the percentage of labeled cells in each layer out of the summed number of layer $2 / 3$ and $4 \mathrm{~B}$ labeled cells (Fig. 11A). In addition, because layer $4 \mathrm{~B}$ is much thinner than layers $2 / 3$, we also calculated the density of label in each layer (see Materials and Methods) and normalized it to the sum of the densities of the two layers, to obtain a DI (Fig. 11B). A DI of 1 for a layer indicates that all labeled cells were in that layer.

We found that, although all stripe types receive the heaviest projection from layer $2 / 3$, the contribution of layer $4 \mathrm{~B}$ varies with stripe type. Specifically, thick stripes received the heaviest projection from layer $4 \mathrm{~B}$, provided that the tracer injection site in V2 involved the infragranular layers (Fig. 10I,J,L) (one additional thick stripe injection case is shown in supplemental Figs. $4 A, D, E$, $7 A, B$, available at www.jneurosci.org as supplemental material). The mean percentage of labeled cells in $4 \mathrm{~B}$ after thick stripe injections $(n=5)$ was $24.4 \%$, and the mean DI equaled 0.41 (Fig. 11 , Table 4). In comparison, the thin (Fig. $10 A-D$ ) and pale (Fig. $10 E-H$ ) stripes received a much smaller projection from layer $4 \mathrm{~B}$, with mean percentages of labeled cells in this layer of $4.3 \%(n=3)$ and $9 \%(n=3)$, respectively, and mean DIs of $\sim 0.2$ (Fig. 11, Table 4). Injections in pale med $_{\text {stripes }}(n=5)$ produced essentially no label in layer 4B (Fig. 10 I, K,L, Table 4) (two additional pale $e_{\text {med }}$ injection cases are shown in supplemental Figs. $4 B-E$ and $7 C, D$, available at www.jneurosci.org as supplemental material).

We noticed that tracer injections that did not involve the V2

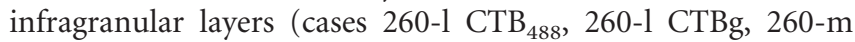
$\mathrm{CTB}_{488}$, and 271-m CTBg) (Tables 1, 4) resulted in smaller numbers of labeled cells in layer 4B, especially after thick stripe injections. For example, case 271-m CTBg (Table 1) showed only a few scattered cells in $4 \mathrm{~B}$, and the two thick stripe injections involving only layers 1-4 (Table 4) showed amounts of layer 4B label comparable with those seen after pale or thin stripe injections. Our interpretation of this finding is that there must be projections from V1 layer $4 \mathrm{~B}$ to the infragranular layers of V2, which are 

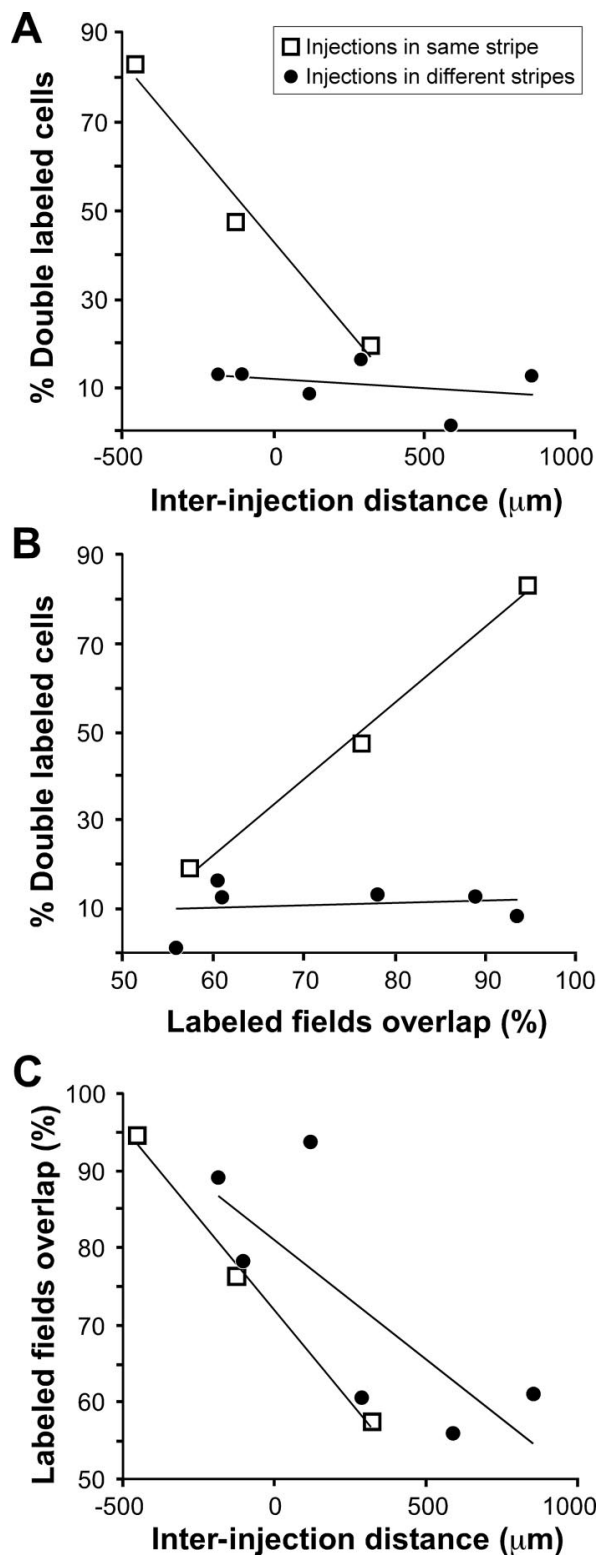

Figure 9. Relationship between interinjection distance, label overlap, and percentage of double-labeled cells resulting from paired injections in same or different stripes. $\boldsymbol{A}$, Scatter plot of percentage of double-labeled cells versus interinjection distance. $\boldsymbol{B}$, Scatter plot of percentage of double-labeled cells versus percentage of overlap between single-labeled fields. C, Scatter plot of percentage of labeled fields overlap versus interinjection distance. Straight lines in $A-C$, Regression lines.

heaviest to the thick stripes. In one thick stripe case (274LH-l) (Table 4), the tracer injection involved only layers $1-3 \mathrm{~B}$, but the relative proportion of resulting label in layers $2 / 3$ vs $4 \mathrm{~B}$ resembled that seen after deep layer injections. Although it is difficult to generalize based on one case, one possibility is that layers $2 / 3$ and $4 \mathrm{~B}$ of V1 contribute equal projections to V2 layers $2 / 3$. Impor-

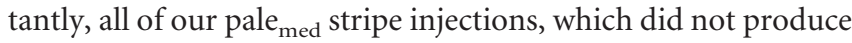
layer 4B label, involved the V2 infragranular layers.

Our counts of labeled cells in layers 5/6 of V1 demonstrated 2.5 and $4.5 \%$ of labeled cells in these layers after injections in pale $_{\text {lat }}$ and thin stripes, respectively, but only when the injection sites involved V2 layer 6. More superficial injections in these stripe types resulted in no labeled cells in V1 layer 5/6, indicating a V1 layer 5/6 to V2 layer 6 projection. In contrast, thick or pale $_{\text {med }}$ stripe injections involving all layers produced little or no labeled V1 layer 5/6 cells (supplemental Table 1, available at www.jneurosci.org as supplemental material).

\section{Population statistics}

Figure 11 and Table 4 summarize our population data on the distribution of cells in V1 layers 2/3 versus $4 \mathrm{~B}$ labeled by tracer injections in each V2 stripe type. The DIs for cases that were quantified were grouped by injected stripe type, and ANOVA contrasts were performed between the groups. The mean DI for each stripe group was significantly different from the mean DI of each other stripe group ( $p<0.006$ ), with the exception

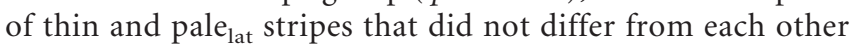
$(p=0.665)$.

These results demonstrate laminar specialization in the V1 output pathways to the V2 stripes.

\section{Discussion}

Our findings recast the V1-to-V2 pathway. Previous studies proposed a tripartite division of this pathway, with each V2 stripe receiving projections from a singleV1 layer: layer $2 / 3$ blobs to thin stripes, layer $2 / 3$ interblobs to pale stripes, and layer $4 \mathrm{~B}$ to thick stripes (Livingstone and Hubel, 1984, 1987). These pathways were thought to maintain beyond V1 the segregation of konio, parvo, and magno geniculocortical channels (Fig. 1A). However, it was later shown that considerable mixing of these three channels occurs within V1 (for review, see Callaway, 2003; Casagrande and $\mathrm{Xu}, 2003$ ) and that all V2 stripes receive projections from the same $\mathrm{V} 1$ layers $(2 / 3,4 \mathrm{~A}, 4 \mathrm{~B}, 5 / 6)$, according to a bipartite scheme: blob columns to thin stripes, and interblob columns to pale and thick stripes (Sincich and Horton, 2002) (Fig. 1B). These new findings challenged parallel processing models of the visual system, suggesting richer intermingling of information beyond V1 and V2. We now show that there are both laminar specialization and tangential segregation in the origin of the V1 output pathways to the V2 stripes, and propose a quadripartite division of the V1-to-V2 pathway (Fig. 12).

We found that, although all stripes receive projections from layers $2 / 3$ and $4 \mathrm{~A}$, layer $4 \mathrm{~B}$ contributes heavy projections to thick stripes, weak projections to thin and pale ${ }_{\text {lat }}$ stripes, and no pro-

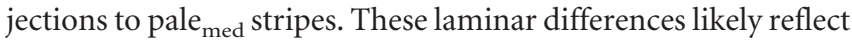
different combinations of magno, parvo, and konio LGN inputs within each V1 output pathway. In particular, the dominant layer $2 / 3$ projection from the interblob to the pale ${ }_{\text {med }}$ stripes, and the lack of $4 \mathrm{~B}$ input to this stripe type, suggest a dominant parvo channel (Yabuta and Callaway, 1998b). Additional studies are needed to determine the downstream areal targets of the pale med $_{\text {m }}$ versus pale $e_{\text {lat }}$ stripes, since previous studies on the connectivity of the V2 stripes did not distinguish between the two sets of pale stripes. These laminar differences in the V1 projections to different V2 stripes were not previously appreciated, likely because previous studies did not quantify the laminar distribution of V1 cells labeled from tracer injections in single stripe types.

A second novel finding of this study is that the V1 interblob region is partitioned into two spatially segregated compartments, one projecting preferentially to the pale stripes, the other to the thick stripes. In particular, our results point at the blob/interblob border region as a novel V1 compartment projecting preferentially to the thick stripes.

Could the segregation of cell label in the middle of the interblob or at the B/I border, after injections in pale or thick stripes, respectively, instead reflect confinement of injection sites to specific V2 orientation-preference domains? This is unlikely for the 

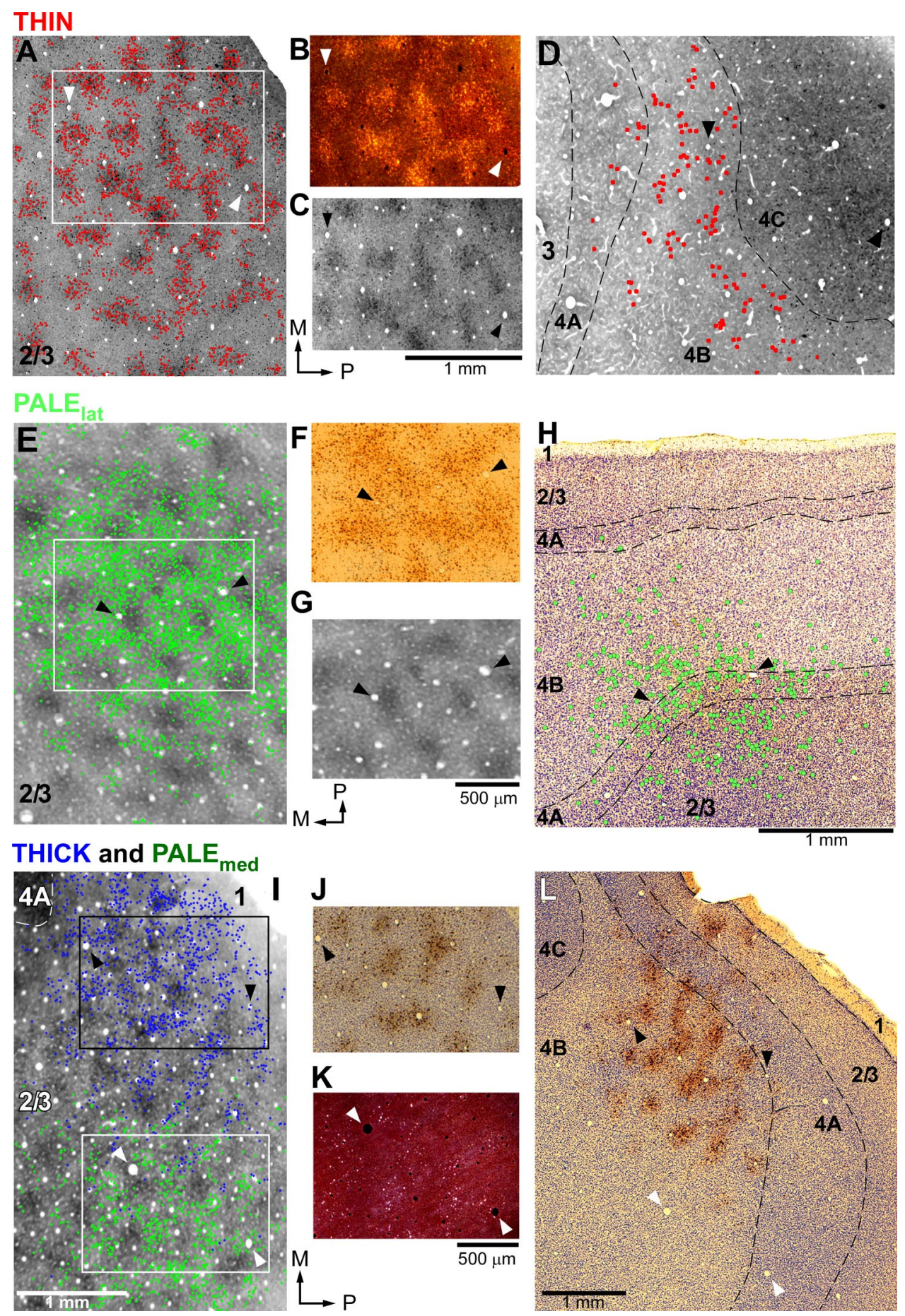

Figure 10. Laminar distribution of V1 cells projecting to different V2 stripes: example cases. A, Case 250 (thin stripe injection). Plots of (TBg-labeled cells (red dots) in V1 layers $2 / 3$ from a single tissue section are shown superimposed to the $\mathrm{C} O \mathrm{image}$ of the same section. This tissue section was reacted for $\mathrm{C} O$ and silver-stained to reveal $\mathrm{CTBg}$. The injection site for this case is shown in Figure $3 A-C . B$, Dark-field image of the area inside the white box in $\boldsymbol{A}$ showing patches of CTBg-labeled cells (gold). $\boldsymbol{C}$, Same section as in $\boldsymbol{B}$ viewed in bright field, showing $\boldsymbol{C} 0$ blobs and CTBg-stained cell bodies inside C 0 blobs. $\boldsymbol{D}$, A deeper tissue section through $\mathrm{V} 1$ layer 4 , stained for $\mathbf{C}$. The location of CTBg-labeled cells in the same section is indicated by red dots. The arrowheads in $\boldsymbol{A}-\boldsymbol{D}$ point at

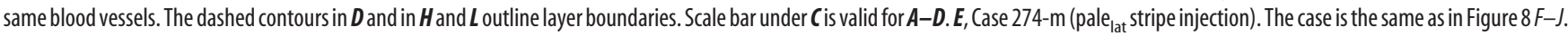
Same conventions as in $\boldsymbol{A}$, but here $\mathrm{CB}_{488}$-labeled cells are shown as green dots and were plotted from an adjacent tissue section. $\boldsymbol{F}$, Higher power, bright-field image of an adjacent tissue section within the white box in $\boldsymbol{E}$ showing $\mathrm{CTB}_{488}$-labeled cells (brown). The pale gray cells interleaved with the brown cells are CTBg-labeled cells resulting from an injection in an adjacent thin stripe (shown in Fig. $8 \mathrm{~F}-\boldsymbol{H}$ ). $\mathbf{G}$, Higher-power $\mathrm{C}$ image of the area inside the white box in $\boldsymbol{E}$. Scale bar under $\boldsymbol{G}$ is valid for $\boldsymbol{F}$ and $\mathbf{G}$. $\boldsymbol{H}$, A deeper tissue section through V1 layers $2 / 3-4 B$, stained for Nissl. The location of $\mathrm{CTB}_{488}$-labeled cells in the same section is indicated by green dots. Scale bar under $\boldsymbol{H}$ is valid for $\boldsymbol{E}$ and $\boldsymbol{H}$. The arrowheads in $\boldsymbol{E}-\boldsymbol{H}$ point at same blood vessels. $\boldsymbol{I}$, Case $271-\mathrm{m}$ (thick stripe injection) and 271-I (pale ${ }_{\text {med }}$ stripe injection). Injection sites for this case are shown in supplemental Figure 6 (available at www.jneurosci.org as supplemental material). Plots of (TB ${ }_{488}$-labeled cells (blue dots) and (TBg-labeled cells (green dots) from a single section through V1 layers 2/3 resulting from a CTB $_{488}$ injection in a thick stripe and a CTBg injection in a pale ${ }_{\text {med }}$ stripe, respectively, are superimposed to an adjacent $\mathrm{C} O$-stained section through layers $2 / 3$. J, Higher power, bright-field image of $\mathrm{CTB}_{488}$-labeled cells (brown) in the section in which cells were plotted, corresponding to the area inside the black box in $\boldsymbol{I}$. $\boldsymbol{K}$, Higher power, dark-field image of the section in which CTBg-labeled cells (white) were plotted, corresponding to the area inside the white box in $\boldsymbol{I} . \boldsymbol{L}$, A deeper tissue section through 11 layers $1-4 B$ immunoreacted for $\mathrm{CTB}_{488}$, silver-reacted for $C T B g$, and counterstained for Nissl. Dense $\mathrm{CTB}_{488}$ label is visible in layer $4 \mathrm{~B}$, but no $C \mathrm{CBg}$ label was present in this layer. The black arrowheads point at same blood vessels in $I, J$, and $\boldsymbol{L}$, whereas the white arrowheads point at same blood vessels (a different, more lateral set) in $I, K$, and $L$. $M, M e d i a l ; P$, posterior. 
Table 4. Laminar distribution of labeled cells in V1: layer 2/3 versus 4B

\begin{tabular}{|c|c|c|c|c|c|c|c|c|c|}
\hline & & Injection sites & & & \% Labeled V1 & cells & Cell density in & & \\
\hline & Case no. & Tracer injected & Layers injected & Diameter (mm) & Layer $2 / 3$ & Layer 4B & Layer $2 / 3$ & Layer 4B & Figures \\
\hline Thin stripes & $250^{a}$ & CTBg & $1-5$ & 0.36 & 93 & 7 & 0.75 & 0.25 & Figs. $3 A-C, 10 A-D$ \\
\hline & $274-\mathrm{m}^{a}$ & $\mathrm{CTBg}$ & $1-6$ & 0.42 & 95 & 5 & 0.77 & 0.23 & Fig. $8 F-H$ \\
\hline & $233^{a}$ & CTB 488 & $1-6$ & 0.57 & 99 & 1 & 0.81 & 0.19 & \\
\hline Thick stripes & $\mathrm{M}^{a}$ & CTB & $1-6$ & $0.87 \times 0.28^{b}$ & 92 & 8 & 0.63 & 0.37 & Fig. $6 A, B, E, F$ \\
\hline & $274 \mathrm{LH}^{a}{ }^{a}$ & FR & $1-3 B$ & 0.21 & 54 & 46 & 0.53 & 0.47 & Fig. $5 A-C$ \\
\hline & $260-\mathrm{m}^{a}$ & $\mathrm{CTBg}$ & $1-5 \mathrm{~A}$ & 0.37 & 92 & 8 & 0.68 & 0.32 & Fig. $8 A-C$ \\
\hline & $271-m^{a}$ & (TB 488 & $1-6$ & 0.35 & 63 & 37 & 0.49 & 0.51 & Fig. $10 I, J, L ;$ s supplemental Fig. $6 A, C$ \\
\hline & $293^{a}$ & $\mathrm{CTBg}$ & $1-6$ & 0.55 & 77 & 23 & 0.62 & 0.38 & Supplemental Figs. $4 A, D, E, 7 A, B^{C}$ \\
\hline & $260-1$ & CTB 488 & $1-4$ & 0.65 & 97 & 3 & 0.83 & 0.17 & \\
\hline & $260-1$ & CTBg & $2-4$ & 0.49 & 98 & 2 & 0.82 & 0.18 & \\
\hline Pale $_{\text {lat }}$ stripes & $260-\mathrm{m}^{a}$ & CTB 488 & $1-4$ & 0.32 & 97 & 3 & 0.86 & 0.14 & Fig. $8 A-C$ \\
\hline & $274-m^{a}$ & CTB 488 & $1-6$ & 0.36 & 94 & 6 & 0.83 & 0.17 & Figs. $8 F-H, 10 E-H$ \\
\hline & $259^{a}$ & $\mathrm{FB}$ & $1-5 \mathrm{~A}$ & 0.52 & 82 & 18 & 0.71 & 0.29 & \\
\hline Pale $_{\text {med }}$ stripes & $282-1^{a}$ & $\mathrm{CTBg}$ & $1-6 \mathrm{~A}$ & 0.41 & 100 & 0 & 1.00 & 0.00 & Fig. $4 A-C$ \\
\hline & $271-I^{a}$ & CTBg & $1-5$ & 0.42 & 99.7 & 0.3 & 0.94 & 0.06 & Fig. $10 I, K, L$; supplemental Fig. $6 B, C$ \\
\hline & $263^{a}$ & $\mathrm{FB}$ & $1-5$ & 1.22 & 100 & 0 & 1.00 & 0.00 & \\
\hline & 293 & CTB 555 & $1-6$ & 0.45 & $>99.5$ & $<0.5$ & & & Supplemental Figs. $4 B, D, E, 7 C, D^{c}$ \\
\hline & $293^{a}$ & DY & $1-6$ & 0.54 & 100 & 0 & 1.00 & 0.00 & Supplemental Figs. $4 C-E, 7 C, D^{C}$ \\
\hline Population (mean & & & & & & & & & \\
\hline Thin stripes & $n=3$ & & & & $95.7 \pm 1.76$ & $4.3 \pm 1.76$ & $0.78 \pm 0.02$ & $0.22 \pm 0.02$ & Fig. 11 \\
\hline Thick stripes & $n=5$ & & & & $75.6 \pm 7.63$ & $24.4 \pm 7.63$ & $0.59 \pm 0.03$ & $0.41 \pm 0.03$ & Fig. 11 \\
\hline Pale $_{\text {lat }}$ stripes & $n=3$ & & & & $91.0 \pm 4.58$ & $9.0 \pm 4.58$ & $0.80 \pm 0.05$ & $0.20 \pm 0.05$ & Fig. 11 \\
\hline Pale $_{\text {med }}$ stripes & $n=4$ & & & & $99.9 \pm 0.08$ & $0.08 \pm 0.08$ & $0.99 \pm 0.02$ & $0.02 \pm 0.02$ & Fig. 11 \\
\hline
\end{tabular}

${ }^{a}$ Cases used for quantitative analysis in Figure 11.

${ }^{b}$ Along versus across stripe.

'Available at www.jneurosci.org as supplemental material.
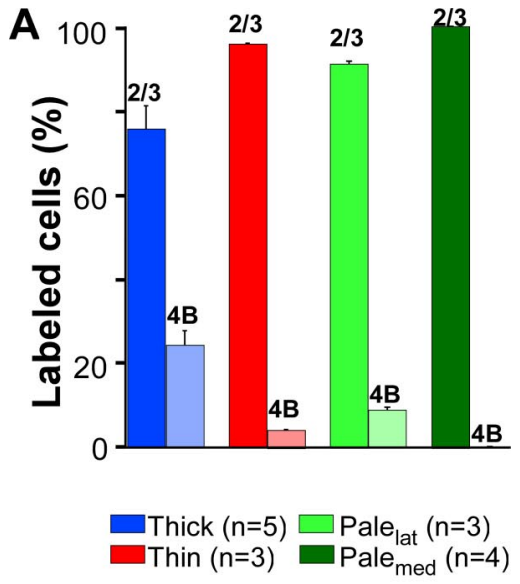

B

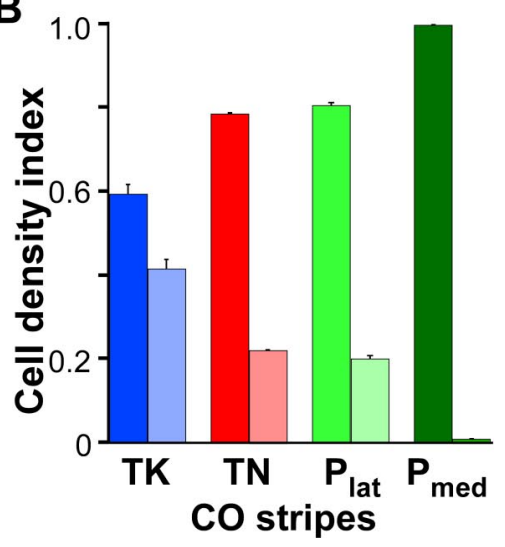

Figure 11. Laminar distribution of V1 cells projecting to different V2 stripes: population data. $\boldsymbol{A}, \boldsymbol{B}$, Population means of the percentage of labeled cells $(\boldsymbol{A})$ and of the cell density index $(\boldsymbol{B})$ in V1 layers $2 / 3$ and $4 B$, grouped by injected stripe type (means and medians are reported in Table 4). TK, TN, $\mathrm{P}_{\text {lat' }}, \mathrm{P}_{\text {med }}$ Thick, thin, pale lat' $_{\text {' }}$ and pale $\mathrm{emed}_{\text {med }}$ stripes, respectively.

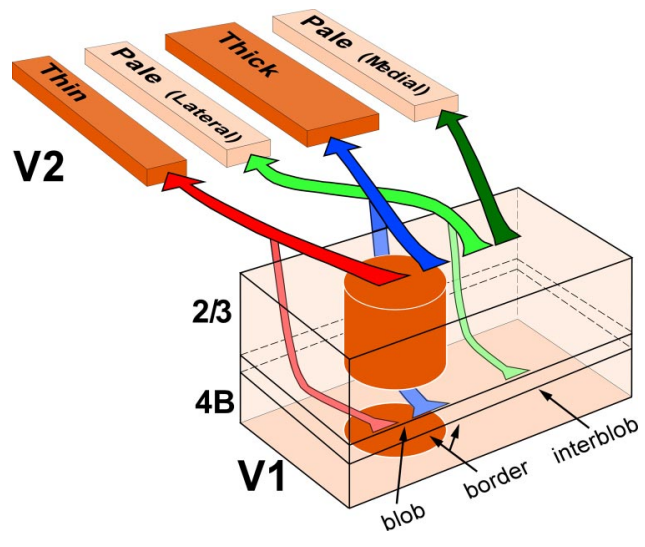

Figure 12. A quadripartite scheme of projections from V1 to V2. Our proposed model of the pathways from $\mathrm{V} 1$ to $\mathrm{V} 2$, based on the present study. Each pathway is represented by arrows of different colors, with darker colors indicating inputs from V1 layers $2 / 3$, and lighter colors those from layer $4 B$. Inputs from layers $4 A$ and $5 / 6$ are omitted for purposes of illustration. The arrow thickness indicates the relative density of projections from layers $2 / 3$ versus $4 B$. C 0 blob columns (i.e., cells in layers $2 / 3$, predominantly, and less so in layers $4 A, 4 B$, and $5 / 6$ ) project to thin stripes (red arrows). Blob/interblob border columns (predominantly from cells in layers $2 / 3$ and $4 B$, and less so from $4 A$ and $5 / 6$ ) project to thick stripes (blue arrows). Interblob columns (predominantly from layers $2 / 3$, less so from $4 A-B$ and 5/6) project to pale ${ }_{\text {lat }}$ stripes (light green arrows). Layer 2/3-4A interblobs project to the pale ${ }_{\text {med }}$ stripes (dark green arrow).

following reasons. First, we and others (Xu et al., 2007; Lu and Roe, 2008) did not observe any bias in the distribution of orientation domains in the interblobs, and both the pale and thick stripes represent a full set of orientations (Fig. $6 F$ ). Second, even if such a bias existed, it is highly unlikely that in different cases we injected the same orientation preference domains in the same stripe type. In fact, in Figure $6 F$, the injection site, which extended $1 \mathrm{~mm}$ along the stripe length, involved a full cycle of 
orientations within the injected V2 thick stripe; yet resulting label in V1 was patchy and densest within the B/I border region (Fig. $6 D, I)$. We conclude that the interblob region is indeed partitioned into two compartments. Could this be a species-specific trait of the marmoset? Although this is a possibility, published data in macaque appear qualitatively consistent with our findings, albeit this was not appreciated by previous authors. For example, Figure 3 in the study by Sincich and Horton (2002) shows an injection of CTBg in a pale stripe next to a WGA (wheat germ agglutinin)-HRP injection in an adjacent thick stripe; patches of labeled cells in V1 arising from the two injections appear mostly interleaved, those from the pale stripe injection predominating in the interblobs and those from the thick stripe injection predominating around blob borders and inside the outer rim of blobs.

Previous anatomical studies in macaque have also suggested that the $\mathrm{B} / \mathrm{I}$ border region may be distinct from the blob and interblob compartments. Yabuta and Callaway (1998b) described a population of cells in midlayer $4 \mathrm{C}$, with somata in $4 \mathrm{C} \beta$ but dendrites extending also in lower $4 \mathrm{C} \alpha$, which project preferentially to the $\mathrm{B} / \mathrm{I}$ border region in layer $3 \mathrm{~B}$. Recent studies have identified a population of highly direction-selective cells in midlayer 4C and in 3B (Gur and Snodderly, 2007, 2008), raising the possibility that this mid-4C-to-3B pathway provides the B/I border region, and therefore the $\mathrm{V} 2$ thick stripes, with high direction selectivity. In a different study, Yabuta and Callaway (1998a) described a population of pyramidal cells in macaque V1 layers $2 / 3$, lacking long-range patchy horizontal connections, whose somata were characteristically located at $130-200 \mu \mathrm{m}$ from blob centers; these cells, like the V1 output cells to the V2 thick stripes in our study, disregarded the blob border and could reside inside or outside blobs. One possibility is that the V1 cells projecting to the thick stripes are these same cells lacking intra-V1 horizontal connections in macaque.

Despite many similarities between the marmoset and macaque visual pathways, there also exist differences. Therefore, we have to allow for the possibility that the organization of V1to-V2 pathways differs in these two primate species. For example, all male and some female marmosets have dichromatic color vision (Travis et al., 1988; Jacobs et al., 1996), which could influence the connectivity of color-processing centers. However, available anatomical and neurochemical studies of the early visual pathway have shown no differences between marmoset dichromats and marmoset trichromats (Ghosh et al., 1996; Wilder et al., 1996; Goodchild and Martin, 1998; Chan et al., 2001; Solomon, 2002) or other diurnal primates (Solomon, 2002). This suggests that the color vision phenotype does not influence the fundamental anatomical organization of the early visual pathway and that the pathways for color vision are not devoted exclusively to the processing of color information (Blessing et al., 2004). However, there have been previous reports of differences between primate species in the connectivity of layer $4 \mathrm{C} \alpha$ (magno) and $4 \mathrm{C} \beta$ (parvo) with blobs versus interblobs, which could affect the relationships between V1 blobs/interblobs and V2 stripes (Boyd et al., 2000). Notably, however, these differences were observed between nocturnal and diurnal primates, and the marmoset, like the macaque is a diurnal primate.

There has been some debate regarding the degree of segregation of the CO blob-to-thin stripe pathway. Xiao and Felleman (2004) found predominant layer 2/3 label in interblobs after pale stripe injections, but an equal number of cells in blobs and interblobs (albeit higher density within blobs) after thin stripe injections. Instead, Sincich and Horton (2005) found strict seg- regation of the blob-to-thin stripe pathway, with $80 \%$ of labeled cells residing in blobs after tracer injections in thin stripes, and $<1 \%$ of double-labeled cells after paired injections of different tracers in adjacent thin and pale stripes. In our study, similar to Sincich and Horton (2005), we find larger percentages of labeled cells in blobs after thin stripe injections. However, consistent with Xiao and Felleman (2004), we do not find strict segregation, as at most $66 \%$ of labeled cells were inside blobs after thin stripe injections. The strict segregation of cell label to blobs found by Sincich and Horton (2005) may be attributable to their exclusion of injection sites ( 9 of 17) that, although confined to a thin stripe, did not reside in the stripe center. Instead, we included all injections that were clearly confined to a stripe type, regardless of their location within the stripe. In general, our results suggest a quadripartite division of pathways from V1 to V2, but also speak against strict spatial segregation of these pathways. Although projections to each V2 stripe arose predominantly from a single V1 compartment, all V1 compartments contributed at least some projections to all V2 stripes. It is possible that the predominant input to a given stripe from a specific V1 compartment reflects the need to maintain clustering within different V2 stripes of stimulus features that are similarly clustered within different V1 compartments [e.g., color or low spatial frequency in the blobs and thin stripes (Landisman and Ts'o, 2002; Xiao et al., 2003, 2007; Tootell et al., 2004)]. However, inputs to any given stripe from all V1 compartments may be needed to segregate and map within single V2 stripe types stimulus features [e.g., binocular retinal disparity in thick stripes (Chen et al., 2008)] that, instead, are not clustered within single V1 compartments (Kara and Boyd, 2009). However, the scarcity of double-labeled cells (up to 8 or $16 \%$, depending on the reference population used to calculate the percentage) (Table 3 ) that we found after paired injections of different tracers in adjacent stripe types indicates that most V1 cells, regardless of their V1 compartment location, project to only a single stripe type. This suggests that thin, thick, and pale stripes receive distinct messages from V1. Sincich and Horton (2002) previously reported 16\% of double-labeled cells (or $33 \%$, depending on reference population), after injections of different tracers in adjacent pale and thick stripes in macaque. Note, however, that their injection sites were considerably larger than in our study and encompassed more than a single stripe.

Although it is the task of future research to elucidate the function of our proposed four V1-to-V2 pathways, our results provide a new foundation for parallel processing models of the visual system.

\section{References}

Angelucci A, Clascá F, Sur M (1996) Anterograde axonal tracing with the subunit B of cholera toxin: a highly sensitive immunohistochemical protocol for revealing fine axonal morphology in adult and neonatal brains. J Neurosci Methods 65:101-112.

Blessing EM, Solomon SG, Hashemi-Nezhad M, Morris BJ, Martin PR (2004) Chromatic and spatial properties of parvocellular cells in the lateral geniculate nucleus of the marmoset (Callithrix jacchus). J Physiol 557:229-245

Boyd JD, Casagrande VA (1999) Relationships between cytochrome oxidase (CO) blobs in primate primary visual cortex (V1) and the distribution of neurons projecting to the middle temporal area (MT). J Comp Neurol 409:573-591.

Boyd JD, Mavity-Hudson JA, Casagrande VA (2000) The connections of layer 4 subdivisions in the primary visual cortex (V1) of the owl monkey. Cereb Cortex 10:644-662.

Brandt HM, Apkarian AV (1992) Biotin-dextran: a sensitive anterograde 
tracer for neuroanatomic studies in rat and monkey. J Neurosci Methods 45:35-40.

Callaway EM (2003) Cell types and local circuits in the primary visual cortex of the macaque monkey. In: The visual neurosciences (Chalupa LM, Werner JS, eds). Cambridge, MA: MIT.

Casagrande VA, Xu X (2003) Parallel visual pathways: a comparative perspective. In: The visual neurosciences (Chalupa LM, Werner JS, eds), pp 494-506. Cambridge, MA: MIT.

Chan TL, Martin PR, Clunas N, Grünert U (2001) Bipolar cell diversity in the primate retina: morphologic and immunocytochemical analysis of a new world monkey, the marmoset Callithrix jacchus. J Comp Neurol 437:219-239.

Chen G, Lu HD, Roe AW (2008) A map for horizontal disparity in monkey V2. Neuron 58:442-450.

Condé F (1987) Further studies on the use of the fluorescent tracers fast blue and diamidino yellow: effective uptake area and cellular storage sites. J Neurosci Methods 21:31-43.

DeYoe EA, Van Essen DC (1985) Segregation of efferent connections and receptive field properties in visual area V2 of the macaque. Nature 317:58-61.

DeYoe EA, Van Essen DC (1988) Concurrent processing streams in monkey visual cortex. Trends Neurosci 11:219-226.

Ericson H, Blomqvist A (1988) Tracing of neuronal connections with cholera toxin subunit B: light and electron microscopic immunohistochemistry using monoclonal antibodies. J Neurosci Methods 24:225-235.

Fritsches KA, Rosa MG (1996) Visuotopic organisation of striate cortex in the marmoset monkey (Callithrix jacchus). J Comp Neurol 372:264-282.

Ghosh KK, Goodchild AK, Sefton AE, Martin PR (1996) Morphology of retinal ganglion cells in a new world monkey, the marmoset Callithrix jacchus. J Comp Neurol 366:76-92.

Goodchild AK, Martin PR (1998) The distribution of calcium-binding proteins in the lateral geniculate nucleus and visual cortex of a New World monkey, the marmoset, Callithrix jacchus. Vis Neurosci 15:625-642.

Gur M, Snodderly DM (2007) Direction-selectivity in V1 of alert monkeys: evidence for parallel pathways for motion processing. J Physiol 585:383-400.

Gur M, Snodderly DM (2008) Physiological differences between neurons in layer 2 and layer 3 of primary visual cortex (V1) of alert macaque monkeys. J Physiol 586:2293-2306.

Horton JC, Hubel DH (1981) Regular patchy distribution of cytochrome oxidase staining in primary visual cortex of macaque monkey. Nature 292:762-764.

Humphrey AL, Hendrickson AE (1983) Background and stimulus-induced patterns of high metabolic activity in the visual cortex (area 17) of the squirrel and macaque monkey. J Neurosci 3:345-358.

Jacobs GH, Neitz M, Deegan JF, Neitz J (1996) Trichromatic color vision in New World monkeys. Nature 382:156-158.

Jeffs J, Ichida JM, Federer F, Angelucci A (2009a) Anatomical evidence for classical and extra-classical receptive field completion across the discontinuous horizontal meridian representation of primate area V2. Cereb Cortex 19:963-981.

Jeffs J, Federer F, Angelucci A (2009b) Anatomical evidence for an area DM, but not V3, bordering dorsal V2 in the marmoset. Soc Neurosci Abstr 35:453.14.

Kara P, Boyd JD (2009) A micro-architecture for binocular disparity and ocular dominance in visual cortex. Nature 458:627-631.

Landisman CE, Ts'o DY (2002) Color processing in macaque striate cortex: relationships to ocular dominance, cytochrome oxidase, and orientation. J Neurophysiol 87:3126-3137.

Livingstone M, Hubel D (1988) Segregation of form, color, movement, and depth: anatomy, physiology, and perception. Science 240:740-749.

Livingstone MS, Hubel DH (1984) Anatomy and physiology of a color system in the primate visual cortex. J Neurosci 4:309-356.

Livingstone MS, Hubel DH (1987) Connections between layer 4B of area 17 and the thick cytochrome oxidase stripes of area 18 in the squirrel monkey. J Neurosci 7:3371-3377.

Llewellyn-Smith IJ, Minson JB, Wright AP, Hodgson AJ (1990) Cholera toxin B-gold, a retrograde tracer that can be used in light and electron microscopic immunocytochemical studies. J Comp Neurol 294:179-191.

Lu HD, Roe AW (2008) Functional organization of color domains in V1 and V2 of macaque monkey revealed by optical imaging. Cereb Cortex $18: 516-533$.
Luppi PH, Fort P, Jouvet M (1990) Iontophoretic application of unconjugated cholera toxin B subunit (CTb) combined with immunohistochemistry of neurochemical substances: a method for transmitter identification of retrogradely labeled neurons. Brain Res 534:209-224.

Lyon DC, Kaas JH (2001) Connectional and architectonic evidence for dorsal and ventral V3, and dorsomedial area in marmoset monkeys. J Neurosci 21:249-261.

Malach R, Tootell RB, Malonek D (1994) Relationship between orientation domains, cytochrome oxidase stripes, and intrinsic horizontal connections in squirrel monkey area V2. Cereb Cortex 4:151-165.

McLoughlin N, Schiessl I (2006) Orientation selectivity in the common marmoset (Callithrix jacchus): the periodicity of orientation columns in V1 and V2. Neuroimage 31:76-85.

Merigan WH, Maunsell JH (1993) How parallel are the primate visual pathways? Annu Rev Neurosci 16:369-402.

Palmer SM, Rosa MG (2006) Quantitative analysis of the corticocortical projections of the middle temporal area in the marmoset monkey: evolutionary and functional implications. Cereb Cortex 16:1361-1375.

Purves D, LaMantia A (1993) Development of blobs in the visual cortex of macaques. J Comp Neurol 334:169-175.

Roe AW, Ts'o DY (1995) Visual topography in primate V2: multiple representation across functional stripes. J Neurosci 15:3689-3715.

Roe AW, Fritsches K, Pettigrew JD (2005) Optical imaging of functional organization of V1 and V2 in marmoset visual cortex. Anat Rec A Discov Mol Cell Evol Biol 287:1213-1225.

Rosa MG, Elston GN (1998) Visuotopic organisation and neuronal response selectivity for direction of motion in visual areas of the caudal temporal lobe of the marmoset monkey (Callithrix jacchus): middle temporal area, middle temporal crescent, and surrounding cortex. J Comp Neurol 393:505-527.

Rosa MG, Schmid LM (1995) Visual areas in the dorsal and medial extrastriate cortices of the marmoset. J Comp Neurol 359:272-299.

Rosa MG, Tweedale R (2000) Visual areas in lateral and ventral extrastriate cortices of the marmoset monkey. J Comp Neurol 422:621-651.

Rosa MG, Fritsches KA, Elston GN (1997) The second visual area in the marmoset monkey: visuotopic organisation, magnification factors, architectonical boundaries, and modularity. J Comp Neurol 387:547-567.

Rosa MG, Palmer SM, Gamberini M, Tweedale R, Piñon MC, Bourne JA (2005) Resolving the organization of the New World monkey third visual complex: the dorsal extrastriate cortex of the marmoset (Callithrix jacchus). J Comp Neurol 483:164-191.

Rosa MG, Palmer SM, Gamberini M, Burman KJ, Yu HH, Reser DH, Bourne JA, Tweedale R, Galletti C (2009) Connections of the dorsomedial visual area: pathways for early integration of dorsal and ventral streams in extrastriate cortex. J Neurosci 29:4548-4563.

Salin PA, Bullier J (1995) Corticocortical connections in the visual system: structure and function. Physiol Rev 75:107-154.

Schiessl I, McLoughlin N (2003) Optical imaging of the retinotopic organization of $\mathrm{V} 1$ in the common marmoset. Neuroimage 20:1857-1864.

Sengpiel F, Troilo D, Kind PC, Graham B, Blakemore C (1996) Functional architecture of area 17 in normal and monocularly deprived marmosets (Callithrix jacchus). Vis Neurosci 13:145-160.

Shipp S, Zeki S (1985) Segregation of pathways leading from area V2 to areas V4 and V5 of macaque monkey visual cortex. Nature 315:322-325.

Shipp S, Zeki S (2002) The functional organization of area V2, I: specialization across stripes and layers. Vis Neurosci 19:187-210.

Sincich LC, Horton JC (2002) Divided by cytochrome oxidase: a map of the projections from V1 to V2 in macaques. Science 295:1734-1737.

Sincich LC, Horton JC (2005) Input to V2 thin stripes arises from V1 cytochrome oxidase patches. J Neurosci 25:10087-10093.

Sincich LC, Jocson CM, Horton JC (2007) Neurons in V1 patch columns project to V2 thin stripes. Cereb Cortex 17:935-941.

Solomon SG (2002) Striate cortex in dichromatic and trichromatic marmosets: neurochemical compartmentalization and geniculate input. J Comp Neurol 450:366-381.

Tootell RB, Silverman MS, De Valois RL, Jacobs GH (1983) Functional organization of the second cortical visual area in primates. Science 220:737-739.

Tootell RB, Nelissen K, Vanduffel W, Orban GA (2004) Search for color "center(s)" in macaque visual cortex. Cereb Cortex 14:353-363. 
Travis DS, Bowmaker JK, Mollon JD (1988) Polymorphism of visual pigments in a callithrichid monkey. Vision Res 28:481-490.

Ungerleider LG, Haxby JV (1994) "What" and "where" in the human brain. Curr Opin Neurobiol 4:157-165.

Vanduffel W, Tootell RB, Schoups AA, Orban GA (2002) The organization of orientation selectivity throughout macaque visual cortex. Cereb Cortex 12:647-662.

Wilder HD, Grünert U, Lee BB, Martin PR (1996) Topography of ganglion cells and photoreceptors in the retin of a New World monkey: the marmoset Callithrix jacchus. Vis Neurosci 13:335-352.

Xiao Y, Felleman DJ (2004) Projections from primary visual cortex to cytochrome oxidase thin stripes and interstripes of macaque visual area 2 . Proc Natl Acad Sci U S A 101:7147-7151.

Xiao Y, Wang Y, Felleman DJ (2003) A spatially organized representation of color in macaque cortical area V2. Nature 421:535-539.
Xiao Y, Casti A, Xiao J, Kaplan E (2007) Hue maps in primate striate cortex. Neuroimage 35:771-786.

Xu X, Bosking W, Sáry G, Stefansic J, Shima D, Casagrande V (2004) Functional organization of visual cortex in the owl monkey. J Neurosci 24:6237-6247.

Xu X, Anderson TJ, Casagrande VA (2007) How do functional maps in primary visual cortex vary with eccentricity? J Comp Neurol 501:741-755.

Yabuta NH, Callaway EM (1998a) Cytochrome-oxidase blobs and intrinsic horizontal connections of layer $2 / 3$ pyramidal neurons in primate $\mathrm{V} 1$. Vis Neurosci 15:1007-1027.

Yabuta NH, Callaway EM (1998b) Functional streams and local connections of layer $4 \mathrm{C}$ neurons in primary visual cortex of the macaque monkey. J Neurosci 18:9489-9499.

Zeki S, Shipp S (1988) The functional logic of cortical connections. Nature 335:311-317. 